\title{
CXCL12 modulation of CXCR4 and CXCR7 activity in human glioblastoma stem-like cells and regulation of the tumor microenvironment
}

\author{
Roberto Würth ${ }^{1,2}$, Adriana Bajetto ${ }^{1,2}$, Jeffrey K. Harrison ${ }^{3}$, Federica Barbieri ${ }^{1,2}$ and Tullio Florio ${ }^{1,2}$ * \\ ' Sezione di Farmacologia, Dipartimento di Medicina Interna, University of Genova, Genova, Italy \\ ${ }^{2}$ Centro di Eccellenza per la Ricerca Biomedica, University of Genova, Genova, Italy \\ ${ }^{3}$ Department of Pharmacology and Therapeutics, College of Medicine, University of Florida, Gainesville, FL, USA
}

\section{Edited by:}

Flavia Trettel, University of Roma

Sapienza, Italy

Reviewed by:

Vedrana Montana, University of

Alabama, USA

Maurizio Grimaldi, Southern Research Institute, USA

\section{*Correspondence:}

Tullio Florio, Sezione di Farmacologia, Dipartimento di Medicina Interna,

University of Genova, Viale Benedetto XV 2, Genova 16132, Italy

e-mail: tullio.florio@unige.it
Chemokines are crucial autocrine and paracrine players in tumor development. In particular, CXCL12, through its receptors CXCR4 and CXCR7, affects tumor progression by controlling cancer cell survival, proliferation and migration, and, indirectly, via angiogenesis or recruiting immune cells. Glioblastoma (GBM) is the most prevalent primary malignant brain tumor in adults and despite current multimodal therapies it remains almost incurable. The aggressive and recurrent phenotype of GBM is ascribed to high growth rate, invasiveness to normal brain, marked angiogenesis, ability to escape the immune system and resistance to standard of care therapies. Tumor molecular and cellular heterogeneity severely hinders GBM therapeutic improvement. In particular, a subpopulation of chemo- and radio-therapy resistant tumorigenic cancer stem-like cells (CSCs) is believed to be the main responsible for tumor cell dissemination to the brain. GBM cells display heterogeneous expression levels of CXCR4 and CXCR7 that are overexpressed in CSCs, representing a molecular correlate for the invasive potential of GBM. The microenvironment contribution in GBM development is increasingly emphasized. An interplay exists between CSCs, differentiated GBM cells, and the microenvironment, mainly through secreted chemokines (e.g., CXCL12) causing recruitment of fibroblasts, endothelial, mesenchymal and inflammatory cells to the tumor, via specific receptors such as CXCR4. This review covers recent developments on the role of CXCL12/CXCR4-CXCR7 networks in GBM progression and the potential translational impact of their targeting. The biological and molecular understanding of the heterogeneous GBM cell behavior, phenotype and signaling is still limited. Progress in the identification of chemokine-dependent mechanisms that affect GBM cell survival, trafficking and chemo-attractive functions, opens new perspectives for development of more specific therapeutic approaches that include chemokine-based drugs.

Keywords: CXCL12, CXCR4, CXCR7, glioblastoma, cancer stem cells

\section{BACKGROUND}

Chemokines (CKs) and their cognate receptors are constitutively expressed in the central nervous system (CNS) where they control complex physiological functions. In particular, the pleiotropic chemokine CXCL12 (formerly known as stromal-cell derived factor-alpha, SDF1- $\alpha$ ) and its receptors CXCR4 and CXCR7 are key regulators in CNS development, and are involved in neuromodulation, neuroprotection, and control the interactions between neurons, microglia and astrocytes in adult brain (Rostene et al., 2007). Altered expression of CXCR4 and CXCL12 has also been associated to CNS diseases, such as HIV encephalopathy, stroke and multiple sclerosis, among others (Bajetto et al., 2001a; Rostene et al., 2011). A role for CXCL12 modulation of CXCR4 and CXCR7 was identified for most of the brain tumors including gliomas, meningiomas and even pituitary adenomas that frequently overexpress these receptors (Bajetto et al., 2007; Barbieri etal., 2007; Duda etal., 2011). In this review we analyze the role of CKs in glioblastoma (GBM) development, diffusion and recurrence.
GBM is the most common and most malignant primary glial tumor in adults, characterized by an invariably poor outcome and limited therapeutic options (Dolecek et al., 2012). Standard GBM management involves maximal surgical resection, followed by radiotherapy with concomitant and adjuvant chemotherapy with temozolomide, but in most cases GBM rapidly relapses. Available treatments at relapse are largely ineffective and median overall survival of GBM patients is about 15 months (Stupp et al., 2005).

There is increasing evidence that tumor development, growth, recurrence and resistance to chemo- and radio-therapy is related to the presence of a cell subpopulation, named cancer stem cells (CSCs), nowadays identified in different human hemopoietic and solid cancers, including GBM. Efficient CSC eradication represents the ineludible goal to prevent tumor relapse and thus a target for all new anticancer approaches.

Beside its functional expression in embryonic pluripotent stem cells, in adults CXCL12/CXCR4/R7 axis controls tissue-specific stem cell proliferation (Singh et al., 2013). Similar functions 
have been hypothesized to occur also in CSCs. Thus the definition of mechanisms and downstream mediators of CXCR4/R7 activation by CXCL12, in normal and malignant differentiated cells, their progenitors, and in normal and CSCs, is highly relevant for both cancer biology and perspective therapeutic targeting.

\section{CXCL12/CXCR4-CXCR7 SIGNALING}

For many years CXCR4 has been considered the unique receptor for CXCL12 and CXCL12 the sole ligand for CXCR4, a singular exception in the CK family that usually shows promiscuous binding within multiple CKs and receptors. Later, CXCR7 (originally named RDC1) was identified as second receptor for CXCL12, showing 10-fold higher affinity for CXCL12 than CXCR4 (Balabanian et al., 2005), CXCR7 is a member of the atypical CK receptor subgroup (ACKR), also including DARC, D6, and CCRL1, that do not activate G-proteins after correct binding with the respective cognate ligand (Bachelerie et al., 2014). ACKR3 has been proposed as the acronym for CXCR7 in this new nomenclature system. Interestingly, CXCL12 shares CXCR7 binding with another CK, CXCL11 (interferon-inducible T-cell $\alpha$ chemoattractant, ITAC) that is also a ligand for CXCR3 (Singh et al., 2013).

In the CXCR7 amino acid sequence, the highly conserved DRYLAIV domain, which controls G-protein binding and activation, is DRYLSIT (Thelen and Thelen, 2008). Typical CK responses, mediated by $\mathrm{G}$ protein activity, such as intracellular $\mathrm{Ca}^{2+}$ mobilization or modulation of adenylyl cyclase activity, are not generated after CXCR7 binding. Due to the absence of Gi-coupling, CXCR7 was initially proposed to be a decoy receptor, acting as a CXCL12 (and CXCL11) scavenger and able to promote ligand internalization and degradation, to reduce CXCR4 activity (Graham et al., 2012). However, the current vision is that this represents only one of the possible mechanisms by which CXCR7 modulates cellular functions (Sanchez-Martin et al., 2013). Emerging evidence suggests that CXCR7 can activate intracellular signaling pathways, and in particular it is able to elicit Akt, MAP kinase (MAPK), and Janus kinase-signal transducer and activator of transcription (JAK/STAT3) activation, either by direct modulation, through a $\beta$-arrestin-dependent pathway (Singh et al., 2013) or after heterodimerization with CXCR4 (Wang et al., 2011; Hattermann and Mentlein, 2013).

CXCL12 is a homeostatic CK, which controls hematopoietic cell trafficking and adhesion, in immune surveillance and development, being constitutively expressed in different organs (e.g., bone marrow, heart, liver, lung, lymph nodes, liver, brain, kidney, pituitary, among others). However, CXCL12 production has been also correlated with pathological processes, such as inflammation, heart failure, cell damage after organ irradiation or during chemotherapy. In particular, CXCL12 secretion is particularly relevant in hypoxic and pro-angiogenic environments within tumors or during autoimmune diseases (Li and Ransohoff, 2009). CXCR4 is also a rather ubiquitous receptor, with a relevant role at the level of endothelial mature and precursor cells and pericytes in healthy conditions and in hypoxic or damaged vascular tissues, including injured carotid arteries and atherosclerotic plaques (Petit et al., 2007).
CXCL12 binding to CXCR4 triggers receptor homo- and heterodimerization, often, but not always, with CXCR7, depending on the co-expression level of receptors (Levoye et al., 2009). Ligand binding changes the CXCR4 three-dimensional conformation favoring heterotrimeric G-proteins GDP/GTP exchange and dissociation into $\alpha$ - and $\beta \gamma$-subunits, that, in turn, activate multiple transductional pathways (Bajetto et al., 2001a): $\alpha_{i}$ subunits inhibit cAMP formation via modulation of adenylyl cyclase activity; the $\alpha_{\mathrm{q}}$-subunit activates the phospholipase C (PLC)- $\beta$, which hydrolyzes PIP2 (phosphatidylinositol 4,5bisphosphate) inducing the generation of diacylglycerol (DAG) and inositol 1,4,5 trisphosphate (IP3) that controls the release of intracellular $\mathrm{Ca}^{2+}$ from ER and the activation of protein kinase $C$; Gai subunits also induce the activation of the transcription factor nuclear factor- $\kappa \mathrm{B}(\mathrm{NF}-\kappa \mathrm{B})$, the $\mathrm{Ca}^{2+}$-dependent tyrosine kinase PYK2, JAK/STAT, and the activation of the phosphoinositide-3 kinase (PI3K)-Akt pathway, leading to cell survival and proliferation. The $\beta \gamma$ dimer, acting as a functional subunit, is involved in Ras activation of ERK1/2 MAPK cascade, leading to changes in gene expression and cell cycle progression. CXCR4 also regulates cell survival by the $\mathrm{G}$ proteindependent activation of JNK and p38 MAPKs. Further, $\beta \gamma$ dimers interact with ion channels and activate PI3K, modulating CXCL12-dependent chemotaxis. CXCL12 also causes CXCR4 desensitization and uncoupling from G-proteins by GPCR kinase (GRK)-dependent phosphorylation and subsequent interaction of CXCR4 with $\beta$-arrestin that mediates internalization of the receptor (Cheng et al., 2000) and targets desensitized CXCR4 to clathrin-coated pits for endocytosis. Moreover, interactions between CXCR4 and $\beta$-arrestin also promote the activation of downstream intracellular mediators including MAPKs (p38, ERK1/2) and CXCL12-dependent chemotaxis (Sun et al., 2002). Cell migration is directed by CXCR4 by the formation of a CK gradient controlled by internalization of CXCL11 or CXCL12 bound to CXCR7, without the generation of intracellular signaling (Luker et al., 2009). The formation of CXCR4-CXCR7 heterodimers, modulates CXCR4 signaling (Levoye et al., 2009) and enhances CXCL12-dependent intracellular $\mathrm{Ca}^{2+}$ mobilization and ERK1/2 phosphorylation (Sierro et al., 2007), while chemotaxis induced by CXCL12 binding to CXCR4 is blocked by CXCR7 when expressed in the same cells (Decaillot et al., 2011). The enhanced activity of CXCR4-CXCR7 heterodimers in recruiting a $\beta$-arrestin complex, provides mechanistic insight into the growth, survival, and migratory advantage provided by CXCR4 and CXCR7 co-expression in cancer cells. $\beta$-arrestin recruitment to the CXCR4/CXCR7 complex enhances downstream, $\beta$-arrestin-dependent cell signaling (ERK1/2, p38, SAPK/JNK), which induces cell migration in response to CXCL12 (Cheng et al., 2000; Sun etal., 2002; Singh et al., 2013). CXCR7 monomers also promote ERK1/2 phosphorylation and nuclear translocation via $G$-protein-independent, $\beta$-arrestin-mediated signaling (Rajagopal etal., 2010; Decaillot et al., 2011). CXCR7 mediates CXCL12 signaling in cultured cortical astrocytes and Schwann cells that co-express CXCR4. Stimulation of astrocytes with CXCL12 activates ERK1/2, Akt but not p38 which was still evident after gene silencing of CXCR4 but fully abrogated by depletion of CXCR7. Conversely, in Schwann cells CXCL12 
triggers also p38 phosphorylation altogether with ERK1/2 and Akt, but these effects require the activation of both receptors (Odemis et al., 2010). A diagram of intracellular transduction pathways related to CXCR4 and CXCR7 activation is depicted in Figure 1.

The interaction of CXCR7 with CXCL11 further complicates this chemokinergic system since CXCL11 also binds CXCR3, to induce either proliferative or growth inhibitory signals, depending on the CXCR3 variant (A or B; Singh etal., 2013). Moreover, besides CXCL11, CXCR3 is also bound by CXCL9 and CXCL10 to promote tumor growth, metastasis, angiogenesis and immune cell infiltration into tumors. GBM expression of CXCR3 was confirmed in human and murine GBM cell lines and its activation promotes proliferation in vitro and experimental tumor progression in vivo (Liu et al., 2011). The biological effects of the above described CK-receptor interactions is strictly related to receptor affinity, crosstalk of shared ligands, and associated intracellular signaling in both normal and tumor cells.

\section{MULTIPLE ROLES OF CXCL12/CXCR4-R7 NETWORK: REGULATION OF EARLY DEVELOPMENT OF THE CNS}

CKs are pivotal regulators of cell migration, adhesion, and proliferation not only during inflammation and immune surveillance but also during CNS development. In particular, beside inflammatory or homeostatic leukocyte migration, CXCL12 retains a primordial role, highly conserved through the evolution, in the regulation of embryonic and adult stem cell directional migration. The first evidence of the function of CXCL12 in neural development was suggested by the lethal phenotype of CXCR4and CXCL12-knockout mice (Ma et al., 1998; Zou et al., 1998), both exhibiting abnormal neuronal migration in the cerebellum, dentate gyrus and dorsal root ganglia, in addition to defective lympho-myelopoiesis, and imperfect vasculature and heart development. During cerebellar development CXCR4-positive granule cell precursors are retained in the external granule layer through their interaction with CXCL12 expressed in the overlying pial meninges, ensuring sufficient cell proliferation and allowing the migration to the internal granule layer only

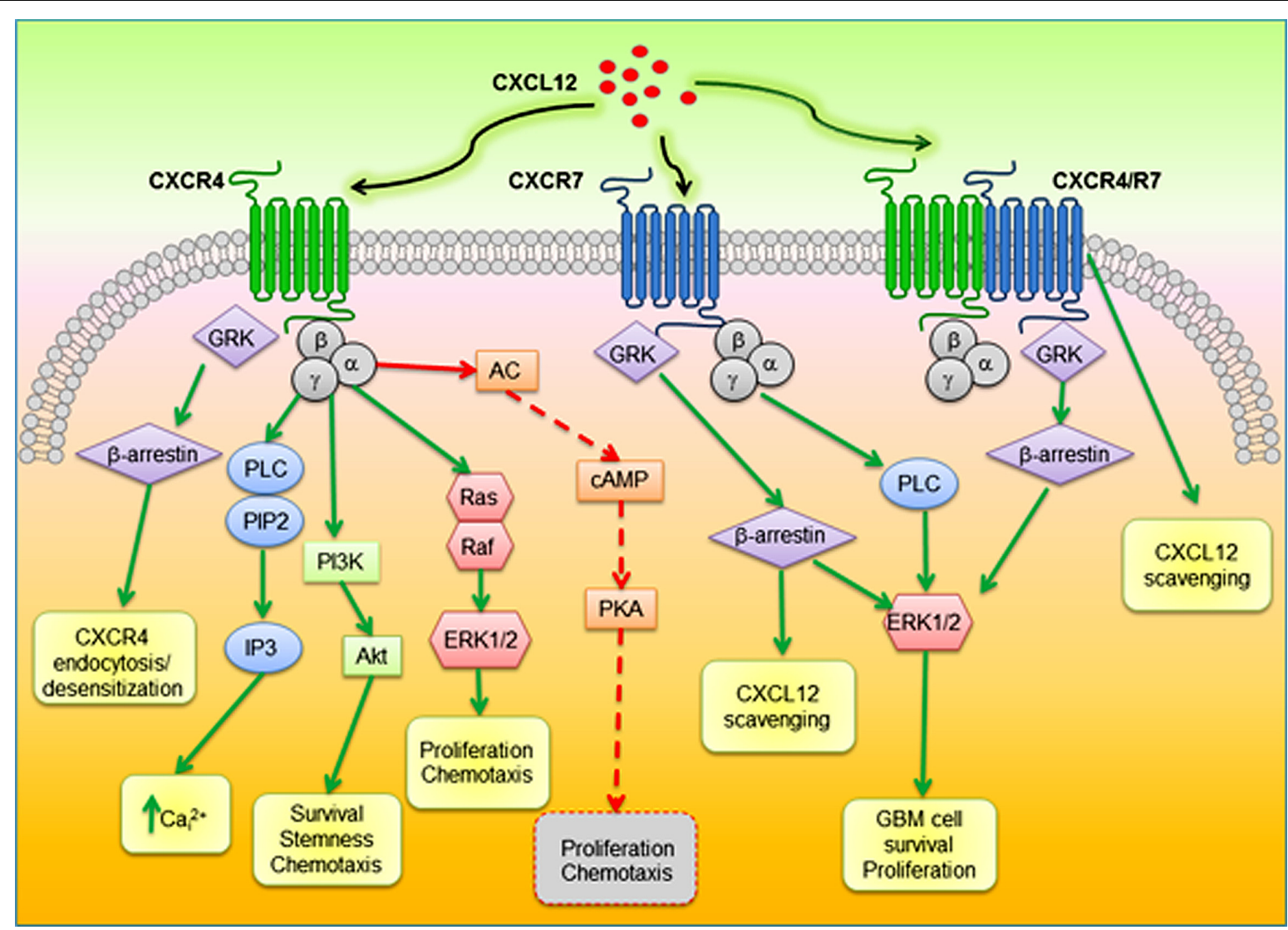

FIGURE 1 | Schematic diagram of proposed CXCR4-CXCR7 crosstalk affecting major signaling pathways related to cell survival, proliferation, and migration. CXCL12 binds to CXCR4 and CXCR7, which can form homodimers or heterodimers. CXCR4-CXCR7 heterodimerization induces a conformational change of CXCR4/G-proteins and blocks signaling. CXCL12-CXCR4 interaction activated by CXCL12 triggers GPCR signaling through PI3K/Akt, PLC/IP3, and ERK1/2 pathways, and mobilization of $\mathrm{Ca}^{2+}$ from endoplasmic reticulum via inhibition of adenyl cyclase mediated CAMP production, thus regulating cell survival, proliferation, and chemotaxis. Beta-arrestin pathway can be activated through GRK to internalize CXCR4 When CXCR7 binds CXCL12, activation of the $\beta$-arrestin may lead to scavenging of CXCL12. In glioblastoma CXCL12/CXCR7 also controls cell survival through ERK1/2. AC, adenylyl cyclase; PLC, phospholipase C; PIP2; phosphatidylinositol 4,5-bisphosphate; IP3, inositol 1,4,5 trisphosphate; PI3K phosphoinositide-3 kinase; ERK1/2, extracellular regulated kinase 1/2; GRK, GPCR kinase 
when the cerebellar cortex is ready to receive them. Altered CXCL12/CXCR4 interaction causes a premature migration of granule precursors and disorganized layer formation (Stumm et al., 2003; Huang et al., 2014). CXCL12 anchors cerebellar granule precursors and favors their proliferation synergistically with Sonic hedgehog (Shh). The CXCL12/CXCR4 axis also controls the tangential migration of post-mitotic neurons (Tiveron et al., 2006).

Thus, CXCL12/CXCR4 signaling regulates the development of many structures in the central and peripheral nervous system, including cerebellum, cortex, hippocampus and dorsal root and sympathetic ganglia, controlling migration and positioning of cerebellar granule cells, Cajal-Retzius cells, cortical interneurons, and hindbrain pontine neurons (Li and Ransohoff, 2009; Zhu et al., 2009; Zhu and Murakami, 2012). CXCL12/CXCR4 regulation of stem cell functioning continues also in adults, in neurogenic niches of brain and bone marrow. Hematopoietic progenitors cells (HPCs) are retained in bone marrow through a CXCR4/CXCL12 interaction that regulates also HPCs homing to this niche after transplantation (Kaplan et al., 2007) survival and proliferation. Interestingly, a similar mechanism has been demonstrated in adult neural progenitor cells (NPCs) or neural stem cells (NSCs; Li and Ransohoff, 2009).

First detected in the 1960s (Altman, 1962), two main areas have been identified in adult mammalian brain where NSCs are localized: the subventricular zone (SVZ) along the lateral walls of the lateral ventricles, and the subgranular zone (SGZ) in the dentate gyrus of hippocampus. NSCs have the potential to self-renew, proliferate, and differentiate into neurons, astrocytes, and oligodendrocytes (Laywell et al., 2007), also in response to ischemic or hypoxic insults (Yang and Levison, 2006; Laywell et al., 2007; Miles and Kernie, 2008; Jin-qiao et al., 2009).

In postnatal brain, CXCR4 expression continues in NPCs in SVZ of lateral ventricle and SGZ of dentate gyrus, the adult brain neurogenic areas, while CXCL12 is expressed in ependymal and endothelial cells adjacent to the proliferating areas. CXCL12 triggers the homing of SVZ NSCs from the ependymal niche to the vascular niche that is abrogated by CXCR4 knockdown. Notably, it has been suggested that the migration of responsive cells to the vascular niche, or non-migration of resting cells in the ependymal niche, is regulated by the levels of CXCL12 in the microenvironment (Miller and Gauthier-Fisher, 2009).

Thus, both in adult and embryonic brain, one of the main physiological roles of the CXCL12/CXCR4 axis is the positioning of NPCs near blood vessels or meninges that provide important source of factors for proliferation and differentiation. Generally, CXCR7 has a more limited and less characterized pattern of expression than CXCR4, and it is primarily involved in vascular and cardiac development, rather than hematopoiesis, as observed in vivo in CXCR7 knockout mice that die at birth from severe heart and vascular defects (Sierro et al., 2007). However, CXCR7 is also expressed during mouse embryogenesis in the neural tube and brain concomitantly with neural crest development and vascularization. (Schonemeier etal., 2008b). During rat brain development, CXCR7 expression starts at E11.5, increases between E15 and E18 in the marginal zone/layer I, and decreases postnatally. In the cerebral cortex, CXCR7 is expressed in GABAergic neuron progenitors, Cajal-Retzus cells, and neural precursors (Schonemeier et al., 2008a).

The molecular function of CXCR7 within the brain has been investigated by studies in zebrafish that provided the first and strong evidence that CXCR7 acts as scavenger receptor, mediating CXCL12 internalization and providing directional cell migration of primordial germ cells to the gonads and the formation of the posterior lateral line. CXCR4 is expressed by migrating cells and CXCR7 acts by sequestrating CXCL12 from non-target areas, allowing the correct cell migration (Dambly-Chaudiere et al., 2007). In the absence of CXCR7, migrating cells still respond to CXCL12, but their movement ends in undesirable sites because of a specific accumulation that prevents the formation of a CXCL12 gradient required for a directional migration. (Boldajipour et al., 2008; Cubedo et al., 2009). In mammals, the scavenger function of CXCR7 has been established in mouse heart valve, as well as umbilical vein endothelial cells (Naumann et al., 2010) and it was shown to be responsible of interneuron migration. Accordingly, CXCR4 and CXCR7 are co-expressed in migrating interneurons but they have a different subcellular localization: CXCR4 in the plasma membrane and CXCR7 in intracellular recycling endosomes (Wang et al., 2011; SanchezAlcaniz etal., 2011). CXCR7 is frequently expressed, in the absence of CXCR4, in forebrain in postnatally generated olfactory interneuron precursors, further demonstrating that CXCR7 is an independent, direct mediator of CXCL12 signaling (Tiveron et al., 2010).

The relevance of CXCL12 and CXCR4/R7, in CNS functions and brain development is even more important considering the consequences of the cancer stem cell hypothesis (Singh et al., 2003, 2004a), based on the concept that tumors derive from cells endowed with stem or stem-like features in which alterations of the self-renewal mechanisms are induced. Therefore, understanding the CK-dependent mechanisms associated with the stemness in normal neural progenitors might help to clarify their activity in cancer development.

\section{ROLE OF CXCL12-CXCR4/R7 IN GLIOBLASTOMA}

CXCL12-CXCR4/R7 system plays a central role in tumor development and tumor cell proliferation, mainly acting via an autocrine/paracrine mechanism, and contributes to the dissemination and invasiveness of several human cancers, including pancreatic, colon, ovarian, prostate, breast, and renal carcinomas, lymphoma, melanoma, neuroblastoma and GBM (Zlotnik, 2006; Barbieri etal., 2010; Lippitz, 2013; Singh et al., 2013). Moreover, less malignant or benign tumors (i.e., pituitary adenomas, meningiomas, etc.) seem to be regulated by the activity of this chemokinergic axis (Bajetto et al., 2007; Barbieri et al., 2008; Wurth et al., 2011).

Additionally, CXCR4 expression in tumor cells was associated with metastasis of many human malignancies (Muller et al., 2001; Ben-Baruch, 2008; Zlotnik, 2008; Ferrari et al., 2012) favoring their migration and homing toward CXCL12 expressing organs (lung, liver, brain, lymph nodes, bone marrow; Teicher and Fricker, 2010). 
The significance of the expression and function of the CXCL12/CXCR4 axis in brain tumors has been intensely investigated in adult and children GBM, astrocytoma, medulloblastoma, oligodendroglioma, and oligodendroastrocytoma (Domanska et al., 2011). In GBM, CXCR4 and CXCL12 are overexpressed in tumor tissue when compared with normal adjacent parenchyma, and their expression level is correlated with tumor grade and poor prognosis (Salmaggi et al., 2005a; Bian et al., 2007). Immunohistochemical studies showed that in GBM CXCR4 and CXCL12 expression does not co-localize with tumor proliferating cells (identified by MIB-1 expressing cells) but they are both mainly localized in hypoxic regions, characterized by necrosis (Rempel et al., 2000; Salmaggi et al., 2005b; Zagzag et al., 2008). In these perinecrotic areas ("pseudopalisading" necrosis), characterized by high cellularity (Rempel et al., 2000; Bajetto et al., 2006; Rong et al., 2006) due to the powerful invasion of glioma cells (Sciume et al., 2010), CXCR4 and CXCL12 co-localize in the same tumor cells (Bajetto et al., 2006). Pseudopalisade areas are peculiar pathologic structures of GBM resulting from a sequence of vascular occlusion and hypoxia (Brat and Van Meir, 2004) leading to migration and accumulation of GBM cells around central necrotic areas and microvascular hyperplasia induced by hypoxic pseudopalisading cells (Jin etal., 2006). Hypoxia promotes GBM angiogenesis, not only via hypoxia-inducible factor- $1 \alpha(\mathrm{HIF}-1 \alpha)$ that directly induces the transcription of VEGF and cytokines (i.e., TNF- $\alpha$ ), and stimulates CXCL12 expression, but also up-regulates CXCR4 expression in pseudopalisades. Thus, CXCL12 drives angiogenesis either directly or in a paracrine manner, supporting tumor growth and GBM cell migration far from hypoxic pseudopalisades, allowing for both necrotic area formation and peripheral invasiveness of GBM.

On the other hand, CXCR4 and CXCL12 expression frequently occurs in GBM proliferating vascular endothelium, but not in endothelial cells from astrocytomas in which proliferation of microvessels is less abundant (Bajetto et al., 2006).

Interestingly, the mechanism of dissemination of glioma cells within the brain, differently from other cancers, does not occur through lymphatic and hematogeneous spread. GBM cells invade the adjacent brain parenchyma with a morphological pattern known as "Scherer's structures" that include normal brain structures (white matter, blood vessels, and parenchyma) where CXCL12 is highly expressed. GBM cells, organized around neuron and blood vessels in subpial regions and in white matter express high levels of CXCR4: VEGF-dependent CXCL12 upregulation in neuronal and endothelial cells induces the migration of CXCR4-positive GBM cells, representing the molecular mechanisms of Scherer's structure formation (Ehtesham et al., 2006; Zagzag etal., 2008; Munson etal., 2013). CXCL12 exerts also pro-angiogenic activity, recruiting CXCR4-positive, circulating bone marrow-derived cells (Petit et al., 2007) and promoting tumor vasculature recovery after irradiation, as a consequence of treatment-induced hypoxia and HIF- $1 \alpha$ activation, which results in increased CXCL12 expression (Jin etal., 2006; Kioi et al., 2010).

The ability of CXCL12 to guide GBM cell migration has been widely supported by in vitro experiments (Rubin et al., 2003;
Bajetto et al., 2006) and, although the molecular mechanisms involved are not definitively identified, the effect of CXCL12 results from a functional cooperation with EGFR and PDGFR, overexpressed in GBM cells (Woerner et al., 2005; Sciaccaluga et al., 2013).

The tumor microenvironment, consisting of constitutive non-cancerous cells (fibroblasts, endothelial cells, and immune cells), as well as connective tissue and extracellular matrix, contributes to GBM (and other solid tumors) development, proliferation, invasiveness and angiogenesis (Domanska et al., 2013). CXCL12/CXCR4 axis acts on the tumor microenvironment through the modulation of the expression and secretion of other CKs (i.e., CCL2, CXCL8) and, concomitantly, CXCR4 expression could be influenced by cytokines (TNF $\alpha$, IFN $\gamma$, IL4-6-10) produced by cells in the microenvironment. These interactions represent an indirect mechanism mediating CXCL12/CXCR4-dependent promotion of survival, proliferation and migration of tumor cells (Zhou et al., 2002; Burger and Kipps, 2006).

Hypoxia enhances CXCL12 secretion in cancer-associated fibroblasts which in turn feeds tumor development either by direct stimulation of tumor cells expressing CXCR4 (paracrine effect) or recruiting endothelial cells for angiogenesis (endocrine effect; Burger and Kipps, 2006). Stromal fibroblasts support the growth of neoplastic cells through elevated secretion of CXCL12 (Orimo et al., 2005), and integrins induce expression of CXCR4 and growth-factor receptors sustaining a pro-survival loop for tumor cells.

The interaction of GBM cells with the microenvironment that protects cancer cells from the chemo- and radio-therapy stress, becomes even more relevant in the context of CXCL12/CXCR4 up-regulation observed after treatment with anticancer drugs, and particularly after anti-VEGF antibodies (Shaked et al., 2008; Kioi et al., 2010; Keunen et al., 2011).

Several studies investigated the signal transduction of the CXCL12/CXCR4 axis in normal glial cells or in cell lines derived from human GBMs, being the expression of ligand and receptor almost always reported. CXCR4 and CXCL12 expression was described in primary cultures of rat type I astrocytes, cortical neurons and cerebellar granule cells and treatment with CXCL12 induced proliferation of normal astrocytes through the activation of ERK1/2 and PI-3K pathways (Bajetto et al., 1999a,b, 2001b). In human GBM cell lines (U87MG, DBTRG-05 and A172), CXCL12 that is released in the extracellular medium, supports cell growth, likely through an autocrine/paracrine mechanism by the activation of intracellular ERK1/2 and Akt pathways (Barbero etal., 2002, 2003). However, differently from normal astrocytes, GBM cell lines show constitutive Akt activation, further increased by CXCL12, and ERK1/2 and Akt are independently involved in cell proliferation. Conversely, the glioma onco-suppressive gene LRRC4 inhibits CXCL12/CXCR4-induced cell proliferation, chemotaxis and invasiveness reducing ERK1/2 and Akt signaling (Wu et al., 2008).

In vivo studies, in which GBM cells are intracerebrally implanted, showed that CXCL12/CXCR4 binding activates matrix metalloproteinases (MMPs) that contribute to the infiltrative 
behavior of GBM cells within the brain parenchyma (Zhang et al., 2005).

While CXCL12/CXCR4 activation within both cancer cells and local stroma clearly contributes to GBM cell proliferation, spreading, and survival to therapy, more recent studies demonstrated that CXCR7 is an alternative, or additional, regulator of GBM growth. CXCR7 is up-regulated in all pathological conditions in which CXCL12 activity is enhanced, including neoplastic diseases, and contributes to tumor growth, adhesion, survival, angiogenesis, and invasion of breast, lung and prostate carcinomas (Miao et al., 2007; Wang et al., 2008) and promotes tumor development in mice (Burns et al., 2006). CXCR7 is highly expressed in tumor endothelial, microglial, and GBM cells (Hattermann et al., 2010). CXCR7 controls tumor diffusion through CXCL12 gradients and it is frequently detected in GBM-associated vasculature (Liu et al., 2010). The increase of CXCR7 expression in microvascular endothelial cells during hypoxia (Schutyser et al., 2007; Monnier et al., 2012) favors CXCL12-induced glioma cell migration (Esencay et al., 2013) facilitating the binding of CXCL12 to endothelial cells (Burns et al., 2006; Liu et al., 2010; Dai et al., 2011) and the activation of CXCL12-mediated cell crossing through endothelium (Mazzinghi et al., 2008; Zabel et al., 2009; Dai et al., 2011).

\section{CXCL12, CXCR4-CXCR7 ACTIVITY IN HUMAN GLIOBLASTOMA STEM-LIKE CELLS}

In recent years, the CSC theory has gained more experimental validation in addition to the refined theoretical definition. In particular, GBM is the tumor histotype that more precisely matches CSC criteria, in terms of heterogeneity and hierarchical organization of cells, identification of stem cell features in tumor cell subpopulations and, importantly, as far as pharmacological responses. Thus, considering the significant role of CXCL12CXCR4/R7 axis in normal stem cell biology, it is evident that this chemokinergic system could play a relevant role in GBM CSCs. Moreover, according to genotypic and phenotypic evidence of a more close reproduction in vitro of the in vivo tumor characteristics of cultures enriched in CSCs, as compared with established cell lines (Lee et al., 2006), recent studies addressed the role of CXCL12 and its receptors in this GBM cell subpopulation (Figure 2).

\section{GLIOBLASTOMA CANCER STEM CELLS}

Glioblastoma is a complex, heterogeneous tissue characterized by the coexistence of several different cell populations with a hierarchical organization. Among them, a relatively small population exhibits stem-like features, including the capacity to persist in a constant number through asymmetric mitotic cell division (self-renewal capacity), thus representing a drug-resistant cell reservoir to generate differentiated cells (multilineage differentiation potential), that in GBM are represented by differentiated progeny expressing either neuronal or glial markers. After the identification of distinctive stem cell markers, these cells were named cancer stem cells (CSCs). Importantly, besides showing NSC properties, CSCs are tumorigenic, phenocopying the original tumor when xenotransplanted in animal models. For this reason, they are also called tumor-initiating cells (TICs), in order to highlight their tumorigenic potential (Florio and Barbieri, 2012). CSCs have been detected in different hematological and solid tumors (Bonnet and Dick, 1997) and the first evidence supporting the presence of CSCs in GBM was reported in 2003 (Singh et al., 2003; Singh et al., 2004b). Several groups have subsequently described the isolation and characterization of GBM CSCs (Hemmati etal., 2003; Bao etal., 2006a; Liu et al., 2006; Bajetto et al., 2013; Griffero etal., 2009). Initially, the phenotypic characterization of GBM CSCs was based on the recognition of distinctive NSC markers, such as nestin, Sox2, Nanog, Oct4, BMI1, musashi-1, but later on, components of pathways active in brain development were found to be expressed in GBM CSCs, including Notch (Wang et al., 2010a), Wnt (Jin et al., 2011), bone morphogenetic protein (BMP; Piccirillo et al., 2006) and TGF- $\beta$ (Ikushima et al., 2009). The five-transmembrane domain glycoprotein CD133 (prominin-1), initially reported as one of the most reliable markers to identify GBM CSCs (Beier et al., 2007), although conflicting reports were subsequently published and not labeling all CSC subpopulations, is still considered a key component of CSCs (Grosse-Gehling et al., 2013) acting as a regulator of cell survival inducing PI3K-Akt activation, via a direct interaction with p85 (Wei et al., 2013).

Conceivably, the plastic phenotype recently proposed for CSCs, rather than unique cellular marker(s), is the most valid hypothesis, also taking into account GBM cell heterogeneity and the high degree of plasticity that favors its aggressive behavior (Florio and Barbieri, 2012; Tang, 2012; Ruiz-Ontanon et al., 2013; Wurth et al., 2014).

The origin of GBM CSCs is still unclear and controversial. CSCs were proposed to derive from normal NSCs after the accumulation of oncogenic mutations and/or following events mediated by the microenvironment (Calabrese et al., 2007; Hjelmeland et al., 2011). More recently, it was suggested that differentiated neurons or astrocytes can be dedifferentiated and transformed, acquiring CSC-like features to originate histologically different GBMs (Friedmann-Morvinski et al., 2012).

Niches are the specific sites where normal stem cells reside and in adult tissues constitute a spatially distinct microenvironment, which contains stromal cells, blood vessels and high concentrations of extracellular matrix proteins and growth factors. The interaction between stem cells and specific niches is critical for the maintenance of their functional properties, and, in particular, for the balance between self-renewal and differentiation that regulates cell number and tissue homeostasis (Ramasamy et al., 2013).

Like NSCs, GBM CSCs require specific niches in which a permissive environment, ensuring the correct combination of supporting cells (endothelial cells, reactive astrocytes, pericytes, tumor-associated macrophages) and extrinsic factors, is essential for their maintenance and regulation.

There are relevant similarities between NSC and CSC niche:

\section{Vasculature}

Blood vessels are an integral component of both neural and cancer stem cell niches. Endothelial cells (EC) modulate NSCs not only by providing oxygen and nutrients, but also through regulation of their capacity to self-renew, proliferate and differentiate (Shen et al., 2004; Charles and Holland, 2010). A comparable and intricate relationship occurs in the niche where CSCs are closely 


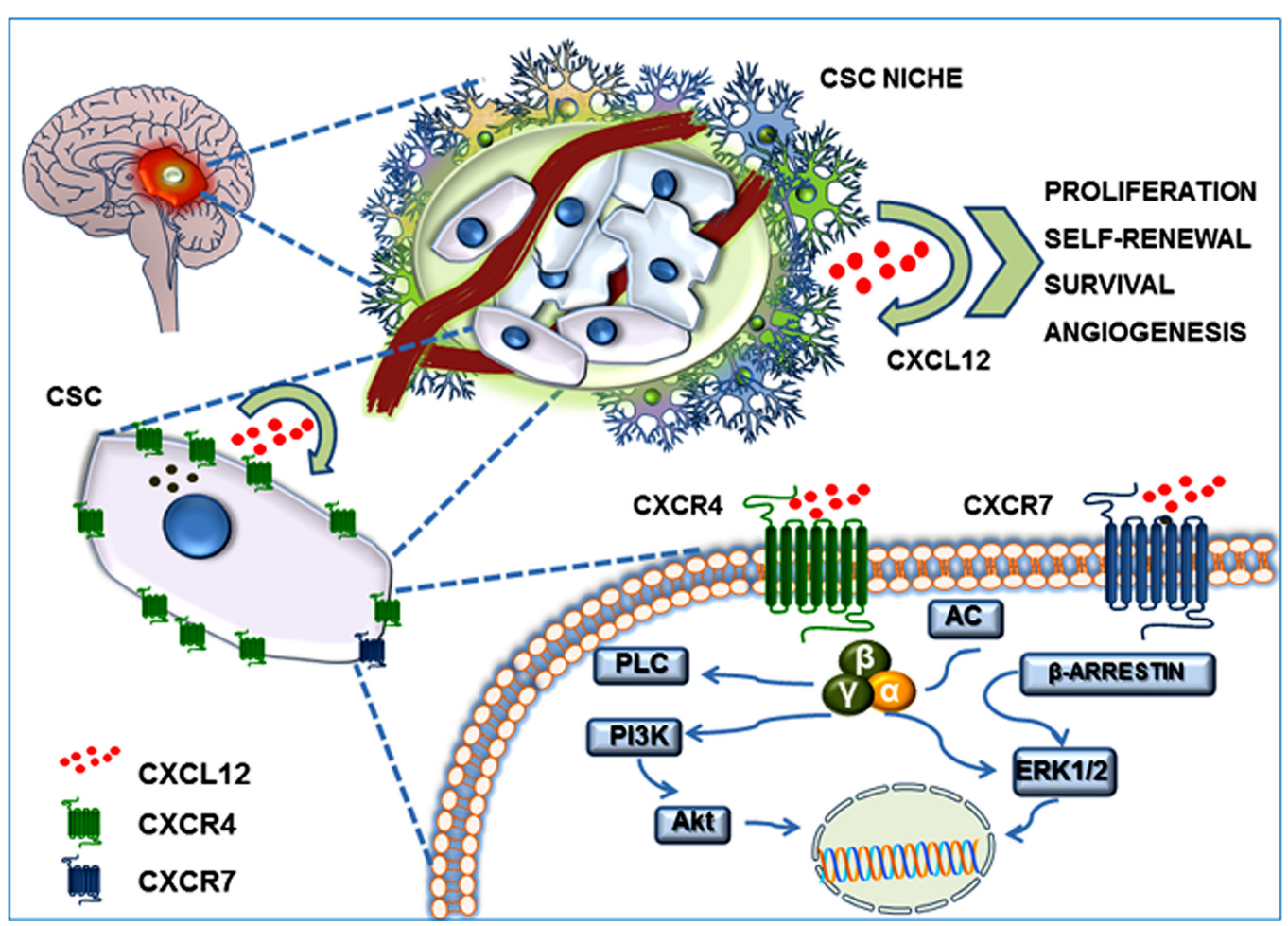

FIGURE 2 | CXCL12/CXCR4-CXCR7 system in the GBM CSC niche. GBM CSC niche is a discrete microenvironment within the tumor mass. It is composed of a heterogeneous cell population that generally includes blood vessels, tumor cells, CSCs, extracellular matrix components, and a gradient of soluble factors. CXCL12 secretion by endothelial cells, tumor cells, and CSCs generates an autocrine and paracrine action which contributes to self-renewal, survival and migration of CSCs themselves, triggering Akt and MAP-kinase(s) intracellular signaling. connected to ECs establishing a paracrine modulation between these two cell types, largely mediated by the secretion of VEGF and CXCL12 (Calabrese et al., 2007; Yao et al., 2013). GBM CSCs not only release growth factors that induce proliferation of ECs (Bao et al., 2006b) but also may be themselves a direct source of angiogenesis by trans-differentiation into endothelial-like cells. On the other hand, ECs maintain CSCs in undifferentiated state, promote their tumorigenicity (Calabrese et al., 2007) and, via the interaction CXCL12-CXCR4, maintain GBM CSCs localized in the perivascular niche (Cheng et al., 2013).

\section{Molecular signaling pathways}

Developmental pathways (Notch, Wnt, Shh), and receptors activated by fibroblast growth factor (FGF), epidermal growth factor (EGF), transforming growth factor (TGF)- $\beta$, and CKs, primarily CXCL12, identified within the niche to maintain NSCs during development and in adult brain, are also involved in CSC survival (Gatti etal., 2013; Penuelas et al., 2009). The interaction between these signal transduction pathways results in self-renewal, sustained proliferation, and increased survival, invasiveness and drug resistance of CSCs (Mimeault et al., 2007).

\section{CXCL12/CXCR4-R7 AXIS IN GBM CSC REGULATION}

As previously detailed, CXCL12 modulates tumor cell proliferation, angiogenesis and metastasis, acting as an autocrine/paracrine growth factor (Barbero et al., 2003; Barbieri et al., 2008; Pattarozzi et al., 2008), representing a promising target for the treatment of neoplasia. The concept of CSCs and their identification in several tumors highlights possible new roles for the CXCL12CXCR4/R7 axis in tumor biology. CXCR4 (over)expression has been detected in CSCs derived from various of cancer histotypes, including pancreatic (Hermann etal., 2007), colon (Zhang et al., 2012), lung (Jung et al., 2013), breast (Dubrovska et al., 2012b) prostate (Dubrovska et al., 2012a), renal (Gassenmaier etal., 2013), and GBM (Singh etal., 2004b). Moreover, the recent demonstration that CXCR7 can also serve as an active receptor for CXCL12 (Odemis etal., 2012) has increased the interest for this chemokinergic system in CSC-related research.

Preclinical studies addressing the role of CXCL12 in GBM CSCs are listed in Table 1 (generated from PubMed, using "CXCL12CXCR4-CXCR7-GBM-CSCs" as keywords).

Criteria used to identify and maintain CSC cultures differ among the various studies, mainly because of the absence of absolute and uniform biomarkers and, different methods of CSC isolation and in vitro culture enrichment have been reported, making study comparisons difficult. Although putative GBM stem-like cells have been isolated as a subpopulation within established cell lines, the isolation of tumor cell subpopulations from human post-surgical explants, grown as non-adherent neurospheres in serum-free medium enriched with growth factors 


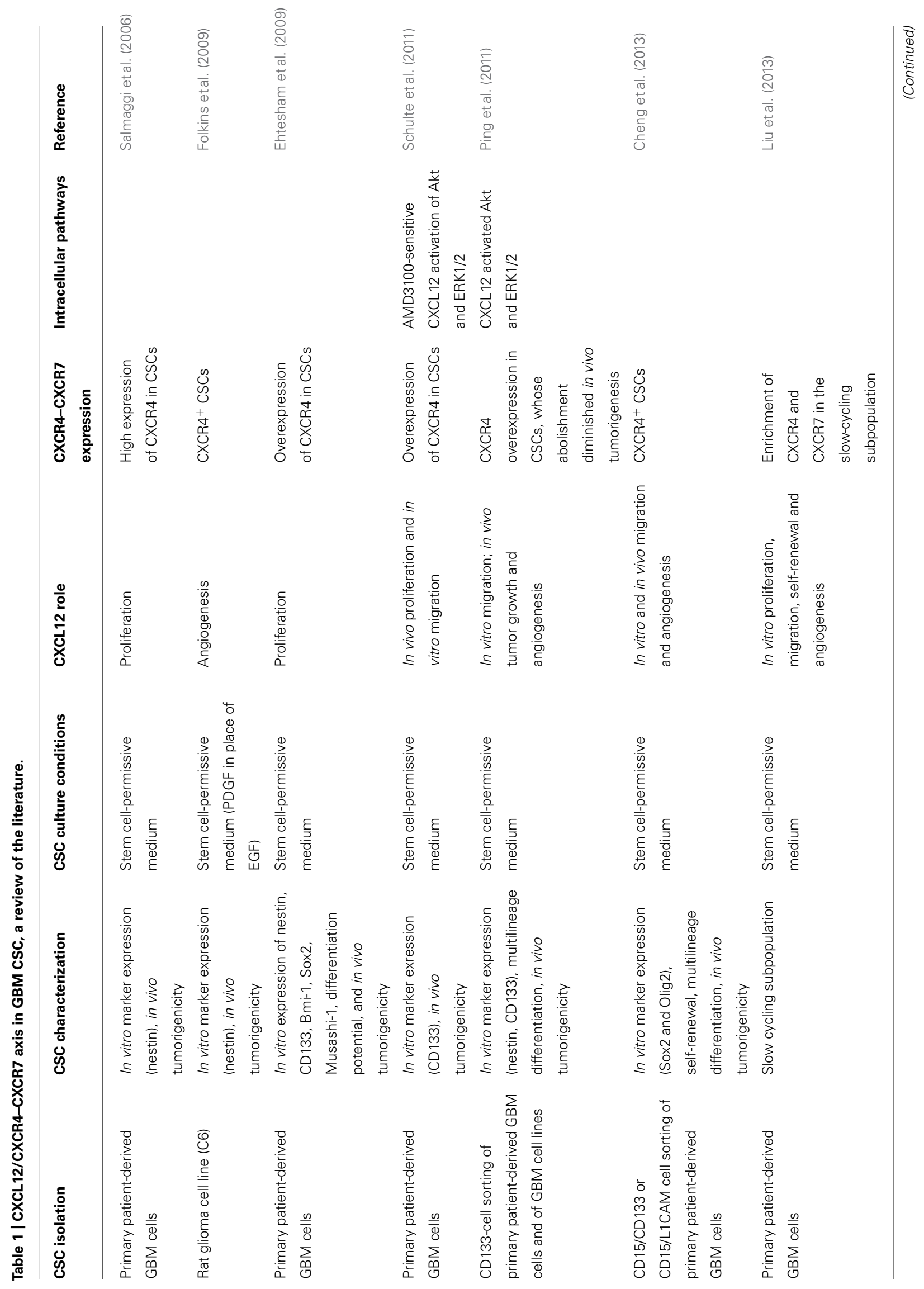




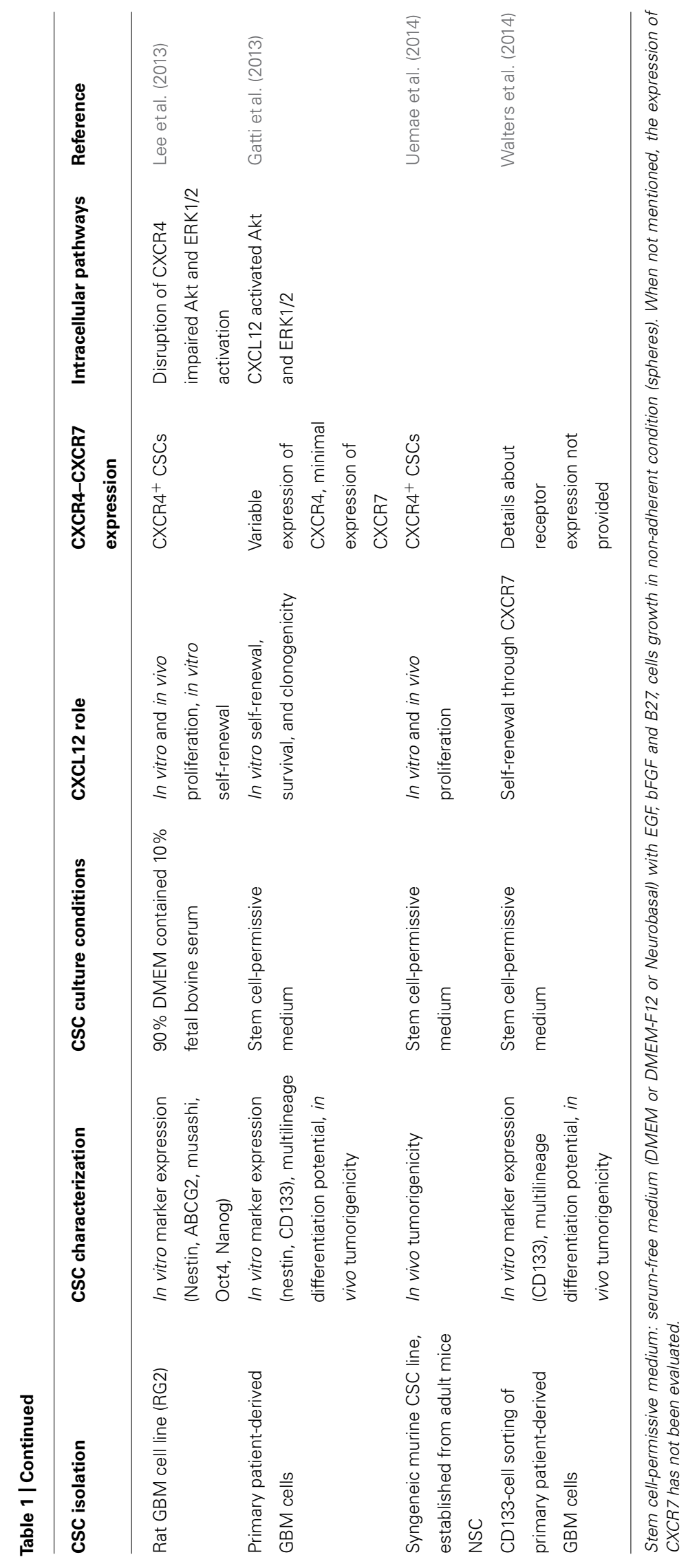


(Folkins et al., 2009), is currently considered the most reliable source of GBM CSCs (Table 1). Long-term passaging of cells in media containing high percentages of serum irreversibly modifies both the phenotype and genotype of the cells as compared to those present in the original tumor, favoring the selection of mutated cells more fit to in vitro growth (Lee et al., 2006; Wakimoto etal., 2012). Moreover, early passage GBM CSCs grown under serum free conditions better recapitulate the in vivo invasive characteristics of the parental tumor when grown as intracranial xenografts, thus making them a more suitable model system.

The selection of tumor cell subpopulations on the basis of the expression of specific biomarkers common to both NSCs and GBM CSCs (in particular CD133 and nestin), could be performed as an additional step. Culture conditions defined for the propagation of NSCs (serum-free medium containing EGF and bFGF) are effective to sustain GBM CSC growth in vitro, allowing cells to grow as floating spheroids (neurospheres) that retain the stem cell phenotype. Noteworthy, neurosphere formation in limiting dilution experiments is one of the main tools used to assess in vitro CSC self-renewal (Carra et al., 2013). Finally, CSC isolation has to be further verified by in vitro/in vivo analysis of functional properties, such as multilineage differentiation and, most importantly, tumorigenicity in animal models.

The CXCL12-CXCR4 axis was reported as a main regulator of GBM CSC biological features: self-renewal, proliferation, migration, angiogenesis, and chemo-and radio-resistance. Overexpression of CXCR4 was observed in GBM CSCs, which increased proliferation in response to exogenous CXCL12 (Ehtesham etal., 2009). However, this CK is also released by CSCs, suggesting an autocrine/paracrine signaling mechanism (Salmaggi et al., 2006; Gatti etal., 2013). CXCR4 activation in GBM CSCs, in combination with VEGF and HGF signaling pathways under hypoxia, is a key factor in determining NSC tropism toward gliomas (Zhao et al., 2008). Further corroboration of these findings came from studies showing higher CXCR4 expression in GBM CSC cultures than in the differentiated tumor cells obtained from the same culture (Ehtesham et al., 2009). These reports paved the way for further studies that revealed high heterogeneity in CXCR4 expression amongst CSC cultures derived from individual human GBMs (Liu et al., 2013). This observation was supported and highlighted in a recent study showing, in five different CSC cultures, that the distinctive properties of original GBM are retained in vitro, including CXCR4 expression and CXCL12 secretion, but were highly variably among cultures, with a general inverse relationship between receptor expression and ligand secretion levels (Gatti et al., 2013).

In vitro, GBM CSC proliferation was induced either by treatment with exogenous CXCL12 (Liu et al., 2013) or by the receptor activation induced by CXCL12 secreted by CSCs in an autocrine fashion (Uemae etal., 2014). This effect was mainly mediated by CXCR4, since it was reversed in the presence of the CXCR4 antagonist AMD3100 (Schulte et al., 2011; Gatti etal., 2013). On the other hand, it was observed that the autocrine effects of CXCL12 promote GBM CSC survival to a higher extent than proliferation: CXCR4 blockade by
AMD3100 reduces CSC survival proportionally to the amount of spontaneously released of CXCL12 (Gatti etal., 2013). The ability of AMD3100 to impair colony formation induced by both exogenous and secreted CXCL12 in GBM CD133positive cells further confirms the autocrine growth-stimulation effect of this CK in this subset of GBM cells (Ping etal., 2011).

The role of CXCL12/CXCR7 axis in GBM CSC biology was only recently investigated and, even if a definitive establishment of its role was not provided, strong evidence supports its involvement in GBM CSC maintenance and tumorigenicity. Pharmacological inhibition of CXCR7 post irradiation caused tumor regression, reduced tumor recurrence, and substantially prolonged survival in a rodent model of GBM, likely interfering with CSCs (Walters et al., 2014). Heterogeneous cell surface expression of CXCR4 and CXCR7, despite similar levels of corresponding mRNAs, was also observed in primary GBM cell cultures. Analysis of cultures enriched in CSCs determined increased percentage of CXCR4and CXCR7-expressing cells suggesting that both receptors might regulate stem phenotype. Heterogeneous functional responses to CXCL12 are evident, with different roles in promoting in vitro cell growth, migration, spherogenesis, and tube formation in individual cultures (Liu et al., 2013). However, CXCR4 ${ }^{+}, \mathrm{CXCR}^{+}$, and $\mathrm{CXCR}^{+} / \mathrm{CXCR}^{+}{ }^{+}$cell subpopulations present in cell cultures are all tumorigenic (Lee et al., 2013; Liu et al., 2013).

Conversely, other studies reported that GBM CSCs do not express, or express at a low level, CXCR7 (Hattermann et al., 2010; Gatti et al., 2013). Moreover, upon GBM CSC differentiation, CXCR4 levels diminish while CXCR7 increases, suggesting a prevalent role for CXCR7 in differentiated GBM cells (Hattermann et al., 2010).

The role of CXCL12-CXCR4 axis in GBM CSCs was corroborated by in vivo studies. In particular, knocking down CXCR4 using RNAi or inhibiting CXCR4 function by AMD3100 in CSCs, impairs proliferation in vivo, effectively reducing tumor growth in two different xenograft models (Ping et al., 2011; Lee et al., 2013); similarly shRNA CXCL12 knock-down in CSCs inhibited tumor growth in vivo (Uemae et al., 2014).

\section{SELF-RENEWAL}

Besides proliferation and survival, CXCL12/CXCR4 axis plays a significant role in maintaining CSC self-renewal. Self-renewal in vitro can be evaluated through sphere formation and clonogenicity assays. These tests were performed in two different models of GBM CSCs (Gatti et al., 2013; Lee et al., 2013) showing that exogenous CXCL12 promoted sphere formation, and that either the pharmacological blockade of CXCR4 by AMD3100 (Gatti et al., 2013) or silencing the receptor (Lee et al., 2013) suppressed CSC sphere-forming ability after serial in vitro passages. The role of CXCL12 in CSC sustained self-renewal was also supported by the observation that disrupting CXCR4 signaling reduces the expression of genes associated with self-renewal activity (i.e., Oct4 and Nanog; Lee et al., 2013). Similarly, CXCR7 inhibition by CCX771 powerfully affects CSC self-renewal (Walters et al., 2014). Taken together, these data suggest that maintenance of stemness of the CSC subpopulation represents a relevant function related to CXCL12 activity. 


\section{MIGRATION}

CXCL12 stimulated in vitro migration of CSCs in a dosedependent manner and co-administration of AMD3100 inhibited peak chemotactic responses. Conversely, the same treatment resulted in minor effects in continuous glioma cell lines, and only in the presence of extremely high concentrations of AMD3100 caused a statistically significant inhibition of migration (Schulte et al., 2011). However, individual CSC cultures displayed heterogeneous responses to CXCL12 in cell migration experiments in vitro. In particular, CXCL12 induced AMD3100-sensitive cell migration only in a subset of CSC cultures tested (Liu et al., 2013).

\section{ANGIOGENESIS}

CSCs are also responsible for the development of GBM microvasculature. Tumor microvessels were demonstrated to have a neoplastic origin, and CSCs have been suggested to transdifferentiate into functional ECs (Rodriguez et al., 2012). It was demonstrated that GBM CSCs contribute to the microvasculature formation by differentiating into ECs in vitro and in vivo, and that GBM mouse xenografts contain human-derived ECs (Ricci-Vitiani et al., 2010; Wang et al., 2010b; Soda et al., 2011). More recently, vascular pericytes localized near ECs, have been suggested as the actual tumor-derived cells in neovessels, and, by lineage tracing in vivo, GBM CSCs have been proposed to be the source of pericytes rather than ECs (Cheng et al., 2013). CXCL12/CXCR4 axis, at least in part, contributes to GBM pericyte formation inducing migration of CXCR4-expressing CSCs toward the perivascular niche, where ECs secrete CXCL12 (Ehtesham et al., 2009; Folkins et al., 2009) and TGF- $\beta$ drives differentiation into mature pericytes (Cheng et al., 2013). Furthermore, CXCL12 stimulates VEGF secretion in CXCR4-expressing, CD133 ${ }^{+}$CSCs from surgical specimens of human GBM and cell lines, promoting tumor angiogenesis via PI3K/AKT signaling (Ping et al., 2011). Discordant findings have been reported using murine GBM stem-like cells, in which endothelial-like differentiation was associated with CXCL12 expression but CXCL12/CXCR4 blockade did not affect either in vitro tube formation or in vivo angiogenesis. Thus autocrine/paracrine CXCL12 regulates GBM murine stem cell proliferation but probably not angiogenesis (Uemae et al., 2014).

\section{TARGETING CXCL12-CXCR4/CXCR7 AXIS IN CANCER: RATIONALE}

The notion that CXCR4/R7 expression in cancer is, in most cases, a negative prognostic factor is well supported (Bian et al., 2007; Maderna etal., 2007). CXCL12/CXCR4 axis is involved in tumor development favoring adaptation, survival and proliferation of cancer cells and CSCs in the tumor environment (Scotton etal., 2002; Zhou etal., 2002; Marchesi etal., 2004) and increasing dissemination of CXCR4-expressing tumor cells in response to CXCL12 gradients (Zlotnik et al., 2011) as CXCL12 is markedly expressed in most common sites of metastasis (liver, brain and bone). Moreover, the pro-angiogenic role of CXCR4/R7 and the ability of CXCL12 to up-regulate and synergize with VEGF support the therapeutic relevance of the pharmacological targeting of this pathway. In particular, CXCL12-CXCR4/R7 axis drives hypoxia-dependent angiogenesis and invasiveness of
GBM progenitor cells (Ehtesham et al., 2009). CXCR4 also sustains non-pharmacological resistance of tumor cells, through its effects on the stromal microenvironment that supplies growthand drug-resistance signals to tumor cells (Burger and Kipps, 2006).

Thus specific targeting of CK receptors or CXCL12 itself in cancer management may provide a valuable tool to modulate autocrine/paracrine signaling networks between cancer cells, CSCs and key stromal components (blood vessels, immune cells, fibroblasts), responsible for tumor cell survival, insufficient drug delivery and reduced efficacy of conventional anticancer drugs. CXCR4/R7-based therapeutics might open up the concept of microenvironment targeted therapy as a new pharmacological strategy, to be used in combination with cytotoxic drugs. Indeed, GBM growth and recurrence relies on CSCs that are responsible for tumor vessel formation and bidirectionally interact with tumor ECs via secreted factors, including CXCL12, to preserve stemness and promote self-renewal (Stupp et al., 2005; Calabrese et al., 2007; Gatti et al., 2013).

\section{CXCR4 ANTAGONISTS IN CANCER MANAGEMENT}

Most findings on the effects of CXCR4 antagonists in human cancer were obtained in hematological malignancies, disrupting the interactions between CXCR4-expressing leukemia cells and CK secreted by the bone marrow microenvironment. Therefore, results may not be directly translated to solid tumors, but findings could give interesting insights into the potential role of drugs targeting CXCR4, as also shown in tumor animal models.

The discovery of CXCR4 as a co-receptor for T-cell tropic HIV1 led to the initial development of CXCR4 antagonists such as T140 (Masuda et al., 1992), AMD3100 (De Clercq et al., 1992) and ALX-4C (Doranz et al., 1997). Subsequently, the identification of non-HIV-related functions boosted new applications of CXCR4 inhibitors such as stem cell mobilization, inflammation and cancer treatments.

CXCR4 antagonists can be classified as: (i) modified peptides (T140 and its analogues, BKT140, POL6326, FC131); (ii) small-molecules CXCR4 antagonists (AMD3100, AMD11070, MSX-122, GSK812397); (iii) CXCL12 peptide analogs (CTCE9908 and CTCE-0214); or (iv) antibodies targeting CXCR4 (MDX-1338/BMS 93656, ALX-0651).

Peptide-based CXCR4 antagonists (TC14012, TZ14001 and TN14003), derived from T140, demonstrated, in preclinical studies, ability to prevent tumor growth and metastasis in animal models of breast, head, and neck carcinoma (Liang et al., 2004; Yoon et al., 2007). In small cell lung cancer cells, TN14003 disrupts CXCR4/CXCL12 interactions and blocks cell adhesion and chemoresistance (Hartmann et al., 2005).

The development of molecules able to inhibit HIV-1/CXCR4 interaction, led to the identification of AMD3100 (De Clercq, 2003), a bicyclam reversible antagonist, the most studied among CXCL12/CXCR4 signaling inhibitors, shown to block CXCL12mediated calcium mobilization, chemotaxis, and GTP-binding. AMD3100 efficacy in hematopoietic stem cell mobilization was tested in two successful randomized phase III clinical trials on HIV-1 patients (DiPersio et al., 2009) and it was approved by FDA and EMA, in association with G-CSF, for autologous bone marrow 
transplantation in multiple myeloma (MM) and non-Hodgkin's lymphoma (NHL)(De Clercq, 2010).

CXCR4 blockade by AMD3100 decreases tumor growth in preclinical GBM models. AMD4365, a novel derivative acting as CXCR4 antagonist inhibits breast tumor formation and reduces lung and liver metastasis (Ling et al., 2013) acting both on tumor and immune cells present in the tumor microenvironment. Association of AMD3100 with bis-chloronitrosourea, showed antitumor efficacy in orthotopic models of GBM demonstrating synergism between CXCR4 inhibition and conventional cytotoxic therapies (Redjal et al., 2006). Currently a combination study with AMD3100 and bevacizumab for patients with recurrent high-grade glioma is ongoing (https://clinicaltrials.gov) with the hypothesis that blockade of CXCR4 will counteract resistance mechanisms to VEGF inhibition. The anti-angiogenic efficacy of AMD3100 was also reported, resulting in a marked reduction of tumor growth and invasiveness in orthotopic GBMxenotransplanted rats (Ali et al., 2013).

MSX-122, a small molecule identified as a "partial CXCR4 antagonist" (biased antagonist) that shows anti-metastatic activity in vivo through the unique property of blocking homing and recruitment of cells without mobilizing stem cells (Liang etal., 2012). MSX-122 also inhibits the development of fibrotic process in mice, after radiation-induced lung injury (Shu et al., 2013).

The orally bioavailable derivative AMD11070 powerfully impairs CXCL12/CXCR4-mediated chemotaxis in vitro (Mosi et al., 2012; O'Boyle et al., 2013), although phase I/II studies did not warrant further development after safety and pharmacokinetics assessment. BKT140, TG-0054, and POL6326 are currently in clinical evaluation as stem cell mobilizers, for MM, leukemias and lymphomas. The safety and efficacy of BKT140 for mobilization of human $\mathrm{CD}_{3}{ }^{+}$cells in patients with $\mathrm{MM}$ has been recently reported (Peled et al., 2014).

CTCE-9908, a CXCL12 modified peptide, beside hematopoietic tumors, is the only CXCR4 antagonist approved analog by FDA for solid tumors, and specifically for the treatment of osteogenic sarcoma. CTCE-9908 inhibits human breast tumor cells growth in mouse xenografts impairing the CXCR4-VEGF loop and lowering tumor VEGF levels (Hassan et al., 2011) and affects breast, prostate and esophageal cancer metastasization in murine models (Wong and Korz, 2008; Richert et al., 2009). Phase I/II clinical trials of this compound, in patients with hepatocellular carcinoma, are currently under evaluation (Wong and Korz, 2008).

The emerging role of CXCR4 in tumor-stroma cross-talk has a great therapeutic potential to deplete minimal residual disease and CSCs: the disruption of CXCR4-mediated tumor cell adhesion to stromal cells might sensitize residual cancer cells and stem cells to standard cytotoxic drugs. In this respect, MDX-1338/BMS 93656, AMD3100 and BKT140 are currently under investigation in phase I/II clinical studies for MM and chronic lymphoid leukemia (CLL).

The development of antibodies against CK receptors has promising therapeutic efficacy, as reported in preclinical and clinical studies. Pharmacological approaches using antibodies exploit a dual mechanism: direct, by selective functional inhibition of the target receptor and, indirect, by potentiation of host immune response through the recruitment of cytotoxic monocytes/macrophages (i.e., antibody-dependent cellmediated cytotoxicity) or by binding complement factors (i.e., complement-dependent toxicity). Several CK-directed (CCL2, CCL5, and CXCL10) antibodies have been generated and tested in phase I/II clinical trials (Klarenbeek etal., 2012) in both cancer and inflammatory diseases. 30D8, a humanized antibody against mouse/human CXCL12, inhibits tumor growth and/or metastasis and improve arthritis in experimental in vitro and in vivo models (Zhong etal., 2013). However, the majority of antibodies that successfully entered clinical trials, targets CK receptors rather than ligands. This development was boosted by the identification of the crystal structure of the receptors, particularly concerning the N-terminal extracellular domain, the most accessible region for antibody binding.

A fully-human CXCR4-targeting moAb, MDX-1338/BMS93656, able to prevent CXCL12 binding, abolished intracellular $\mathrm{Ca}^{2+}$ increase and chemotaxis induced by CXCL12 and it is under study to treat relapsed leukemia or, in combination with lenalidomide/dexamethasone or bortezomib/dexamethasone, relapsed/refractory MM (Kuhne et al., 2013).

A new class of antibody-derived therapeutics, based on single-domain heavy-chain ( $\mathrm{VHH}$ ) antibody fragment, named nanobodies, displays high stability, low toxicity and antigenbinding capacity. The first CK receptor targeted nanobody against CXCR4 (Jahnichen et al., 2010), showed 100-fold higher affinity than AMD3100. CXCR4 nanobodies completely inhibit entry of CXCR4-tropic HIV-1 strains in vitro and intravenous injection mobilizes stem cell in animal models, acting similarly to AMD3100 (Jahnichen et al., 2010). Currently, a CXCR4-inhibiting nanobody, ALX-0651, is in phase I trial (https://clinicaltrials.gov: NCT01374503).

Recent insights in structural features of both CXCR4 and CXCL12 and structure-activity relationships, improved chemical modeling and structure-based development of candidate molecules to be screened as CXCR4-antagonists (Wu et al., 2010). A virtual screening of the National Cancer Institute's Open Chemical Repository Collection, using a homology model of CXCR4, led to the identification of a lead structure (Kim et al., 2012). Furthermore, a new family of CXCR4 modulators, as phianidine A, identified by screening a library of marine compounds using a simple pharmacophoric model identified after CXCR4 crystal structure, was recently reported (Vitale et al., 2013).

\section{CXCR7 ANTAGONISTS}

In addition to CXCR4, CXCR7 represents a viable target for anticancer and antimetastatic drugs. Inhibition of CXCR7 with selective antagonists in mice engrafted with breast and lung cancer cell lines and experiments testing overexpression or silencing of CXCR7 in tumor cells, collectively support the idea that CXCR7 promotes tumor growth (Miao et al., 2007).

CXCR7 antagonists are expected to act mainly by reducing tumor cell extravasation and thus metastasis, and blocking tumor angiogenesis, as demonstrated by CCX771, a synthetic CXCR7 
ligand markedly more potent at inhibiting transendothelial migration than AMD3100. It also stimulates $\beta$-arrestin recruitment to CXCR7 in a lymphoblastic leukemia model (Zabel et al., 2009). Moreover, exposure of $\mathrm{CXCR}^{+}{ }^{+} \mathrm{CXCR}^{+}$cancer cells to CXCL12 greatly enhances migration of human Burkitt's lymphoma cells through a human HUVEC endothelial cell monolayer as in vitro model of transendothelial migration (Zabel et al., 2011) suggesting the potential efficacy of CXCR7 antagonists in blocking CXCL12mediated metastatic spread of CXCR $4^{+} \mathrm{CXCR} 7{ }^{+}$tumor cells, in vivo.

CXCR7 is also an attractive therapeutic target for hematopoietic stem cell (HSC) mobilization-inducing agents since its expression might be necessary to direct HSCs to the niches sustaining their capacity of migration. Although CXCR7 regulation of BMSC niche has not been completely defined, it should represent a relevant goal for research since the possible inclusion of CXCR7 antagonists in the current formulation of HSC mobilizers (granulocyte-colonystimulating factor, G-CSF, plus AMD3100) might reduce the percentage of patients in which that mobilization protocol fails (To et al., 2011).

In order to fully elucidate the complex pharmacology and potential therapeutic utility of CXCR7 receptor antagonists, CXCR7 structural models would be highly useful. However, these detailed structures are currently not available. At present, a limited number of CXCR7 ligands have been reported (Kalatskaya etal., 2009; Gravel etal., 2010; Wijtmans et al., 2012), therefore the application of GPCR homology modeling and virtual screening, previously used in CXCR4 studies, for novel CXCR7 ligand identification represents a promising tool (Yoshikawa et al., 2013). AMD3100 and the peptidomimetic CXCR4 antagonist TC14012 have also been reported to act as partial CXCR7 agonists (Kalatskaya etal., 2009; Gravel etal., 2010). Several pharmacological studies with small-molecule CXCR7 antagonists endowed with reasonable affinities have been reported, but none disclosed a structure for the antagonists (Burns et al., 2006; Zabel et al., 2009; Hattermann et al., 2010; Rajagopal et al., 2010; Cruz-Orengo et al., 2011). A recent paper describes the first reported combined synthetic, modeling and pharmacological effort on small molecules targeting CXCR7 (Wijtmans et al., 2012).

\section{DUAL TARGETING OF CXCR4-R7 OR CXCL12 BLOCKADE}

Since CXCR4 and CXCR7 are both involved in cancer malignancy, and in particular in GBM angiogenesis, molecules able to interact and block either CXCL12 itself or both receptors simultaneously could represent an improved pharmacological approach (Duda et al., 2011; Singh et al., 2013).

However, as far as dual receptor binding the current available data are rather complex. Some CXCR4 or CXCR7 antagonists were reported to bind also the other receptor although not always acting as antagonist, but partial agonist activity was reported. This is also the case for the prototype CXCR4 antagonist AMD3100 that may act as CXCR7 partial agonist (Kalatskaya etal., 2009). Moreover, CXCR7 agonists selectively activating $\beta$-arestin were shown to down-regulate CXCR4 (Uto-Konomi etal., 2013). This differential modulatory effect on the receptors might induce complex biological responses according to the cell analyzed. As far as GBM it was reported that CSCs mainly express CXCR4 while CXCR7 is mainly located in differentiated cells and endothelia (Hattermann et al., 2010; Gatti et al., 2013). In other models the receptors are co-expressed, acting also as heterodimers. Thus, the potential synergism induced by ligands with dual specificity has to be evaluated in the specific cell context and in relation to the agonist/antagonist properties of the molecule.

A more defined picture is obtainable blocking the activity of both CXCR4 and CXCR7 interfering with their ligand. Indeed, synthetic compounds from the family of chalcones, able to bind to CXCL12 with high affinity to prevent its binding to the receptors, have been reported to inhibit inflammatory responses in eosinophils (Hachet-Haas et al., 2008).

Moreover, NOX-A12, an RNA oligonucleotide that binds and neutralizes CXCL12 with high affinity (Liang et al., 2007), is currently in clinical trial for leukemia and MM, displaying antineoplastic activity and stem cell-mobilization from bone marrow. NOX-A12 interferes with CLL cell motility and BMSC-mediated drug resistance, sensitizing CLL cells towards bendamustine and fludarabine, in BMSC co-cultures. Noteworthy, NOX-A12 has been recently reported to be effective in inhibiting or delaying recurrences following irradiation in an in vivo GBM model (Liu et al., 2014).

\section{CONCLUSION}

In recent years, molecularly targeted drugs have joined conventional chemo- and radio-therapies for the management of several cancers, and have become the first-line treatments for tumors lacking efficacious therapeutic options, such as the approval of bevacizumab for recurrent GBM. Benefits of targeted therapy in terms of overall survival are modest, however in GBM, whose median survival is approximately 15 months, even an improvement of progression-free survival could be encouraging. In this context, the blockade of CXCR4/R7 signaling represents an alternative or additional target for neo-adjuvant treatments. However, a better understanding of the biology of the CK receptors and ligands in CSCs, GBM tissue and stroma, is needed to clarify their role in tumorigenesis and define the actual best therapeutic target among stromal cells, CSC and differentiated cancer cells or their whole cross-talk. In addition, since CXCR4 and CXCR7 are involved in angiogenesis, targeting this chemokinergic system could improve the poor efficacy of inhibitors of angiogenesis in several cancers including GBM.

Conceivably, the combination of CXCR4 and CXCR7 antagonists could represent powerful tool to reduce tumor cell invasion and metastasis. Moreover, the role of CXCL12 pathway in tumor resistance, acting both directly, to promote cancer cell and CSC survival and angiogenesis, and indirectly, to recruit stromal cells that through paracrine activity induce recurrence and metastasis, is crucial for cancer therapy.

However, development of preclinical and translational research targeting microenvironment in hematopoietic and solid malignancies should be paralleled by solution of its limitations as the actual benefit of combination with cytotoxic agents, duration (length) of responses and potential development of mechanisms 
of resistance. Moreover, each cancer type might require a different CXCR4 antagonist, exploiting pharmacological features such as oral availability and pharmacokinetics, and the prevalent ability to mobilize hematopoietic cells or to inhibit metastasis or invasion of cancer cells.

\section{ACKNOWLEDGMENTS}

This work was supported by grants from Italian Association for Cancer Research (AIRC) and Compagnia di San Paolo to Tullio Florio, and the Florida Center for Brain Tumor Research (FCBTR) to Jeffrey K. Harrison.

\section{REFERENCES}

Ali, M. M., Kumar, S., Shankar, A., Varma, N. R., Iskander, A. S., Janic, B., et al. (2013). Effects of tyrosine kinase inhibitors and CXCR4 antagonist on tumor growth and angiogenesis in rat glioma model: MRI and protein analysis study. Transl. Oncol. 6, 660-669. doi: 10.1593/tlo.13559

Altman, J. (1962). Are new neurons formed in the brains of adult mammals? Science 135, 1127-1128. doi: 10.1126/science.135.3509.1127

Bachelerie, F., Graham, G. J., Locati, M., Mantovani, A., Murphy, P. M., Nibbs, R., et al. (2014). New nomenclature for atypical chemokine receptors. Nat. Immunol. 15, 207-208. doi: 10.1038/ni.2812

Bajetto, A., Bonavia, R., Barbero, S., Florio, T., and Schettini, G. (2001a). Chemokines and their receptors in the central nervous system. Front. Neuroendocrinol. 22, 147-184. doi: 10.1006/frne.2001.0214

Bajetto, A., Barbero, S., Bonavia, R., Piccioli, P., Pirani, P., Florio, T., et al. (2001b). Stromal cell-derived factor-lalpha induces astrocyte proliferation through the activation of extracellular signal-regulated kinases $1 / 2$ pathway. J. Neurochem. 77 , 1226-1236. doi: 10.1046/j.1471-4159.2001.00350.x

Bajetto, A., Barbieri, F., Dorcaratto, A., Barbero, S., Daga, A., Porcile, C., et al. (2006). Expression of CXC chemokine receptors 1-5 and their ligands in human glioma tissues: role of CXCR4 and SDF1 in glioma cell proliferation and migration. Neurochem. Int. 49, 423-432. doi: 10.1016/j.neuint.2006.03.003

Bajetto, A., Barbieri, F., Pattarozzi, A., Dorcaratto, A., Porcile, C., Ravetti, J. L., et al. (2007). CXCR4 and SDF1 expression in human meningiomas: a proliferative role in tumoral meningothelial cells in vitro. Neuro Oncol. 9, 3-11. doi: 10.1215/15228517-2006-023

Bajetto, A., Bonavia, R., Barbero, S., Florio, T., Costa, A., and Schettini, G. (1999a). Expression of chemokine receptors in the rat brain. Ann. N. Y. Acad. Sci. 876, 201-209. doi: 10.1111/j.1749-6632.1999.tb07640.x

Bajetto, A., Bonavia, R., Barbero, S., Piccioli, P., Costa, A., Florio, T., et al. (1999b). Glial and neuronal cells express functional chemokine receptor CXCR4 and its natural ligand stromal cell-derived factor 1. J. Neurochem. 73, 2348-2357. doi: 10.1046/j.1471-4159.1999.0732348.x

Bajetto, A., Porcile, C., Pattarozzi, A., Scotti, L., Aceto, A., Daga, A., et al. (2013). Differential role of EGF and BFGF in human GBM-TIC proliferation: relationship to EGFR-tyrosine kinase inhibitor sensibility. J. Biol. Regul. Homeost. Agents 27, 143-154.

Balabanian, K., Lagane, B., Infantino, S., Chow, K. Y., Harriague, J., Moepps, B., et al. (2005). The chemokine SDF-1/CXCL12 binds to and signals through the orphan receptor RDC1 in T lymphocytes. J. Biol. Chem. 280, 35760-35766. doi: 10.1074/jbc.M508234200

Bao, S., Wu, Q., McLendon, R. E., Hao, Y., Shi, Q., Hjelmeland, A. B., et al. (2006a). Glioma stem cells promote radioresistance by preferential activation of the DNA damage response. Nature 444, 756-60. doi: 10.1038/nature05236

Bao, S., Wu, Q., Sathornsumetee, S., Hao, Y., Li, Z., Hjelmeland, A. B., et al. (2006b). Stem cell-like glioma cells promote tumor angiogenesis through vascular endothelial growth factor. Cancer Res. 66, 7843-7848. doi: 10.1158/00085472.CAN-06-1010

Barbero, S., Bajetto, A., Bonavia, R., Porcile, C., Piccioli, P., Pirani, P., et al. (2002). Expression of the chemokine receptor CXCR4 and its ligand stromal cell-derived factor 1 in human brain tumors and their involvement in glial proliferation in vitro. Ann. N. Y. Acad. Sci. 973, 60-69. doi: 10.1111/j.1749-6632.2002.tb0 4607.x

Barbero, S., Bonavia, R., Bajetto, A., Porcile, C., Pirani, P., Ravetti, J. L., et al. (2003). Stromal cell-derived factor lalpha stimulates human glioblastoma cell growth through the activation of both extracellular signal-regulated kinases $1 / 2$ and Akt. Cancer Res. 63, 1969-1974.

Barbieri, F., Bajetto, A., and Florio, T. (2010). Role of chemokine network in the development and progression of ovarian cancer: a potential novel pharmacological target. J. Oncol. 2010, 426956. doi: 10.1155/2010/ 426956

Barbieri, F., Bajetto, A., Porcile, C., Pattarozzi, A., Schettini, G., and Florio, T. (2007). Role of stromal cell-derived factor 1 (SDF1/CXCL12) in regulating anterior pituitary function. J. Mol. Endocrinol. 38, 383-389. doi: 10.1677/JME06-0014

Barbieri, F., Bajetto, A., Stumm, R., Pattarozzi, A., Porcile, C., Zona, G., et al. (2008). Overexpression of stromal cell-derived factor 1 and its receptor CXCR4 induces autocrine/paracrine cell proliferation in human pituitary adenomas. Clin. Cancer Res. 14, 5022-5032. doi: 10.1158/1078-0432.CCR-07-4717

Beier, D., Hau, P., Proescholdt, M., Lohmeier, A., Wischhusen, J., Oefner, P. J., et al. (2007). CD133(+) and CD133(-) glioblastoma-derived cancer stem cells show differential growth characteristics and molecular profiles. Cancer Res .67, 4010-4015. doi: 10.1158/0008-5472.CAN-06-4180

Ben-Baruch, A., (2008). Organ selectivity in metastasis: regulation by chemokines and their receptors. Clin. Exp. Metastasis 25, 345-356. doi: 10.1007/s10585-0079097-3

Bian, X. W., Yang, S. X., Chen, J. H., Ping, Y. F., Zhou, X. D., Wang, Q. L., et al. (2007). Preferential expression of chemokine receptor CXCR4 by highly malignant human gliomas and its association with poor patient survival. Neurosurgery 61, 570-578; discussion 578-579. doi: 10.1227/01.NEU.0000290905.53 685.A2

Boldajipour, B., Mahabaleshwar, H., Kardash, E., Reichman-Fried, M., Blaser, H., Minina, S., et al. (2008). Control of chemokine-guided cell migration by ligand sequestration. Cell 132, 463-473. doi: 10.1016/j.cell.2007.12.034

Bonnet, D., and Dick, J. E. (1997). Human acute myeloid leukemia is organized as a hierarchy that originates from a primitive hematopoietic cell. Nat. Med. 3, 730-7. doi: 10.1038/nm0797-730

Brat, D. J., and Van Meir, E. G. (2004). Vaso-occlusive and prothrombotic mechanisms associated with tumor hypoxia, necrosis, and accelerated growth in glioblastoma. Lab. Invest. 84, 397-405. doi: 10.1038/labinvest.3700070

Burger, J. A., and Kipps, T. J. (2006). CXCR4: a key receptor in the crosstalk between tumor cells and their microenvironment. Blood 107, 1761-1767. doi: 10.1182/blood-2005-08-3182

Burns, J. M., Summers, B. C., Wang, Y., Melikian, A., Berahovich, R., Miao, Z., et al. (2006). A novel chemokine receptor for SDF-1 and I-TAC involved in cell survival, cell adhesion, and tumor development. J. Exp. Med. 203, 2201-2213. doi: 10.1084/jem.20052144

Calabrese, C., Poppleton, H., Kocak, M., Hogg, T. L., Fuller, C., Hamner, B., et al. (2007). A perivascular niche for brain tumor stem cells. Cancer Cell 11, 69-82. doi: 10.1016/i.ccr.2006.11.020

Carra, E., Barbieri, F., Marubbi, D., Pattarozzi, A., Favoni, R. E., Florio, T., et al. (2013). Sorafenib selectively depletes human glioblastoma tumor-initiating cells from primary cultures. Cell Cycle 12, 491-500. doi: 10.4161/cc.23372

Charles, N., and Holland, E. C. (2010). The perivascular niche microenvironment in brain tumor progression. Cell Cycle 9, 3012-3021. doi: 10.4161/cc.9.15.12710

Cheng, L., Huang, Z., Zhou, W., Wu, Q., Donnola, S., Liu, J. K., et al. (2013). Glioblastoma stem cells generate vascular pericytes to support vessel function and tumor growth. Cell 153, 139-152. doi: 10.1016/j.cell.2013.02.021

Cheng, Z. J., Zhao, J., Sun, Y., Hu, W., Wu, Y. L., Cen, B., et al. (2000). beta-arrestin differentially regulates the chemokine receptor CXCR4-mediated signaling and receptor internalization, and this implicates multiple interaction sites between beta-arrestin and CXCR4. J. Biol. Chem. 275, 2479-2485. doi: 10.1074/jbc.275.4.2479

Cruz-Orengo, L., Chen, Y. J., Kim, J. H., Dorsey, D., Song, S. K., and Klein, R. S. (2011). CXCR7 antagonism prevents axonal injury during experimental autoimmune encephalomyelitis as revealed by in vivo axial diffusivity. $J$ Neuroinflammation 8, 170. doi: 10.1186/1742-2094-8-170

Cubedo, N., Cerdan, E., Sapede, D., and Rossel, M. (2009). CXCR4 and CXCR7 cooperate during tangential migration of facial motoneurons. Mol. Cell Neurosci. 40, 474-484. doi: 10.1016/j.mcn.2009.01.003

Dai, X., Tan, Y., Cai, S., Xiong, X., Wang, L., Ye, Q., et al. (2011). The role of CXCR7 on the adhesion, proliferation and angiogenesis of endothelial progenitor cells. J. Cell Mol. Med. 15, 1299-12309. doi: 10.1111/j.1582-4934.2011.01301.x 
Dambly-Chaudiere, C., Cubedo, N., and Ghysen, A. (2007). Control of cell migration in the development of the posterior lateral line: antagonistic interactions between the chemokine receptors CXCR4 and CXCR7/RDC1. BMC Dev. Biol. 7:23. doi: 10.1186/1471-213X-7-23

De Clercq, E., Yamamoto, N., Pauwels, R., Baba, M., Schols, D., Nakashima, H., et al. (1992). Potent and selective inhibition of human immunodeficiency virus (HIV)1 and HIV-2 replication by a class of bicyclams interacting with a viral uncoating event. Proc. Natl. Acad. Sci. U. S. A. 89, 5286-5290. doi: 10.1073/pnas.89. 12.5286

De Clercq, E. (2003). The bicyclam AMD3100 story. Nat. Rev. Drug Discov. 2, 581-587. doi: 10.1038/nrd1134

De Clercq, E. (2010). Recent advances on the use of the CXCR4 antagonist plerixafor (AMD3100, Mozobil) and potential of other CXCR4 antagonists as stem cell mobilizers. Pharmacol. Ther. 128, 509-518. doi: 10.1016/j.pharmthera.2010.08.009

Decaillot, F. M., Kazmi, M. A., Lin, Y., Ray-Saha, S., Sakmar, T. P., and Sachdev, P. (2011). CXCR7/CXCR4 heterodimer constitutively recruits betaarrestin to enhance cell migration. J. Biol. Chem. 286, 32188-32197. doi 10.1074/jbc.M111.277038

DiPersio, J. F., Stadtmauer, E. A., Nademanee, A., Micallef, I. N., Stiff, P. J., Kaufman, J. L., et al. (2009). Plerixafor and G-CSF versus placebo and G-CSF to mobilize hematopoietic stem cells for autologous stem cell transplantation in patients with multiple myeloma. Blood 113, 5720-5726. doi: 10.1182/blood-2008-08174946

Dolecek, T. A., Propp, J. M., Stroup, N. E., and Kruchko, C. (2012). CBTRUS statistical report: primary brain and central nervous system tumors diagnosed in the United States in 2005-2009. Neuro Oncol. 14(Suppl. 5), 1-49. doi: 10.1093/neuonc/nos218

Domanska, U. M., Kruizinga, R. C., den Dunnen, W. F., Timmer-Bosscha, H., de Vries, E. G., and Walenkamp, A. M. (2011). The chemokine network, a newly discovered target in high grade gliomas. Crit. Rev. Oncol. Hematol. 79, 154-163. doi: 10.1016/j.critrevonc.2010.07.006

Domanska, U. M., Kruizinga, R. C., Nagengast, W. B., Timmer-Bosscha, H., Huls, G., de Vries, E. G., et al. (2013). A review on CXCR4/CXCL12 axis in oncology: no place to hide. Eur. J. Cancer 49, 219-230. doi: 10.1016/j.ejca.2012.05.005

Doranz, B. J., Grovit-Ferbas, K., Sharron, M. P., Mao, S. H., Goetz, M. B., Daar, E. S., et al. (1997). A small-molecule inhibitor directed against the chemokine receptor CXCR4 prevents its use as an HIV-1 coreceptor. J. Exp. Med. 186, 1395-1400. doi: 10.1084/jem.186.8.1395

Dubrovska, A., Elliott, J., Salamone, R. J., Telegeev, G. D., Stakhovsky, A. E., Schepotin, I. B., et al. (2012a). CXCR4 expression in prostate cancer progenitor cells. PLoS ONE 7:e31226. doi: 10.1371/journal.pone.0031226

Dubrovska, A., Hartung, A., Bouchez, L. C., Walker, J. R., Reddy, V. A., Cho, C. Y., et al. (2012b). CXCR4 activation maintains a stem cell population in tamoxifenresistant breast cancer cells through AhR signalling. Br. J. Cancer 107, 43-52. doi: 10.1038/bjc.2012.105

Duda, D. G., Kozin, S. V., Kirkpatrick, N. D., Xu, L., Fukumura, D., and Jain, R. K. (2011). CXCL12 (SDF1alpha)-CXCR4/CXCR7 pathway inhibition: an emerging sensitizer for anticancer therapies? Clin. Cancer Res. 17, 2074-2080. doi: 10.1158/1078-0432.CCR-10-2636

Ehtesham, M., Mapara, K. Y., Stevenson, C. B., and Thompson, R. C. (2009). CXCR4 mediates the proliferation of glioblastoma progenitor cells. Cancer Lett. 274, 305-312. doi: 10.1016/j.canlet.2008.09.034

Ehtesham, M., Winston, J. A., Kabos, P., and Thompson, R. C. (2006). CXCR4 expression mediates glioma cell invasiveness. Oncogene 25, 2801-2806. doi: 10.1038/sj.onc. 1209302

Esencay, M., Sarfraz, Y., and Zagzag, D. (2013). CXCR7 is induced by hypoxia and mediates glioma cell migration towards SDF-1alpha. BMC Cancer 13:347. doi: 10.1186/1471-2407-13-347

Ferrari, A., Petterino, C., Ratto, A., Campanella, C., Wurth, R., Thellung, S., et al. (2012). CXCR4 expression in feline mammary carcinoma cells: evidence of a proliferative role for the SDF-1/CXCR4 axis. BMC Vet. Res. 8:27. doi: 10.1186/1746-6148-8-27

Florio, T., and Barbieri, F. (2012). The status of the art of human malignant glioma management: the promising role of targeting tumor-initiating cells. Drug Discov. Today 17, 1103-1110. doi: 10.1016/j.drudis.2012.06.001

Folkins, C., Shaked, Y., Man, S., Tang, T., Lee, C. R., Zhu, Z., et al. (2009). Glioma tumor stem-like cells promote tumor angiogenesis and vasculogenesis via vascular endothelial growth factor and stromal-derived factor 1. Cancer Res. 69, 72437251. doi: 10.1158/0008-5472.CAN-09-0167

Friedmann-Morvinski, D., Bushong, E. A., Ke, E., Soda, Y., Marumoto, T., Singer, O., et al. (2012). Dedifferentiation of neurons and astrocytes by oncogenes can induce gliomas in mice. Science 338, 1080-1084. doi: 10.1126/science.12 26929

Gassenmaier, M., Chen, D., Buchner, A., Henkel, L., Schiemann, M., Mack, B., et al. (2013). CXC chemokine receptor 4 is essential for maintenance of renal cell carcinoma-initiating cells and predicts metastasis. Stem Cells 31, 1467-1476. doi: 10.1002/stem.1407

Gatti, M., Pattarozzi, A., Bajetto, A., Wurth, R., Daga, A., Fiaschi, P., et al. (2013). Inhibition of CXCL12/CXCR4 autocrine/paracrine loop reduces viability of human glioblastoma stem-like cells affecting self-renewal activity. Toxicology 314, 209-220. doi: 10.1016/j.tox.2013.10.003

Graham, G. J., Locati, M., Mantovani, A., Rot, A., and Thelen, M. (2012). The biochemistry and biology of the atypical chemokine receptors. Immunol. Lett. 145, 30-38. doi: 10.1016/j.imlet.2012.04.004

Gravel, S., Malouf, C., Boulais, P. E., Berchiche, Y. A., Oishi, S., Fujii, N., et al. (2010). The peptidomimetic CXCR4 antagonist TC14012 recruits beta-arrestin to CXCR7: roles of receptor domains. J. Biol. Chem. 285, 37939-37943. doi: 10.1074/jbc.C110.147470

Griffero, F., Daga, A., Marubbi, D., Capra, M. C., Melotti, A., Pattarozzi, A., et al. (2009). Different response of human glioma tumor-initiating cells to epidermal growth factor receptor kinase inhibitors. J. Biol. Chem. 284, 7138-7148. doi: 10.1074/jbc.M807111200

Grosse-Gehling, P., Fargeas, C. A., Dittfeld, C., Garbe, Y., Alison, M. R., Corbeil, D., et al. (2013). CD133 as a biomarker for putative cancer stem cells in solid tumours: limitations, problems and challenges. J. Pathol. 229, 355-378. doi: 10.1002/path.4086

Hachet-Haas, M., Balabanian, K., Rohmer, F., Pons, F., Franchet, C., Lecat, S., et al. (2008). Small neutralizing molecules to inhibit actions of the chemokine CXCL12. J. Biol. Chem. 283, 23189-23199. doi: 10.1074/jbc.M803947200

Hartmann, T. N., Burger, J. A., Glodek, A., Fujii, N., and Burger, M. (2005). CXCR4 chemokine receptor and integrin signaling co-operate in mediating adhesion and chemoresistance in small cell lung cancer (SCLC) cells. Oncogene 24, 4462-4471. doi: 10.1038/sj.onc.1208621

Hassan, S., Buchanan, M., Jahan, K., Aguilar-Mahecha, A., Gaboury, L., Muller, W. J. et al. (2011). CXCR4 peptide antagonist inhibits primary breast tumor growth, metastasis and enhances the efficacy of anti-VEGF treatment or docetaxel in a transgenic mouse model. Int. J. Cancer 129, 225-232. doi: 10.1002/ijc.25665

Hattermann, K., and Mentlein, R. (2013). An infernal trio: the chemokine CXCL12 and its receptors CXCR4 and CXCR7 in tumor biology. Ann. Anat. 195, 103-110. doi: 10.1016/j.aanat.2012.10.013

Hattermann, K., Held-Feindt, J., Lucius, R., Muerkoster, S. S., Penfold, M. E., Schall, T. J., et al. (2010). The chemokine receptor CXCR7 is highly expressed in human glioma cells and mediates antiapoptotic effects. Cancer Res. 70, 3299-3308. doi: 10.1158/0008-5472.CAN-09-3642

Hemmati, H. D., Nakano, I., Lazareff, J. A., Masterman-Smith, M., Geschwind, D. H., M. Bronner-Fraser, et al. (2003). Cancerous stem cells can arise from pediatric brain tumors. Proc. Natl. Acad. Sci. U. S. A. 100, 15178-15183. doi: 10.1073/pnas. 2036535100

Hermann, P. C., Huber, S. L., Herrler, T., Aicher, A., Ellwart, J. W., Guba, M., et al. (2007). Distinct populations of cancer stem cells determine tumor growth and metastatic activity in human pancreatic cancer. Cell Stem Cell 1, 313-323. doi: 10.1016/j.stem.2007.06.002

Hjelmeland, A. B., Wu, Q., Heddleston, J. M., Choudhary, G. S., MacSwords, J., Lathia, J. D., et al. (2011). Acidic stress promotes a glioma stem cell phenotype. Cell Death Differ. 18, 829-840. doi: 10.1038/cdd.2010.150

Huang, G. J., Edwards, A., Tsai, C. Y., Lee, Y. S., Peng, L., Era, T., et al. (2014) Ectopic cerebellar cell migration causes maldevelopment of purkinje cells and abnormal motor behaviour in CXCR4 null mice. PLoS ONE 9:e86471. doi: 10.1371/journal.pone.0086471

Ikushima, H., Todo, T., Ino, Y., Takahashi, M., Miyazawa, K., and Miyazono, K. (2009). Autocrine TGF-beta signaling maintains tumorigenicity of gliomainitiating cells through Sry-related HMG-box factors. Cell Stem Cell 5, 504-514. doi: 10.1016/j.stem.2009.08.018

Jahnichen, S., Blanchetot, C., Maussang, D., Gonzalez-Pajuelo, M., Chow, K. Y., Bosch, L., etal. (2010). CXCR4 nanobodies (VHH-based single variable 
domains) potently inhibit chemotaxis and HIV-1 replication and mobilize stem cells. Proc. Natl. Acad. Sci. U.S.A. 107, 20565-20570. doi: 10.1073/pnas.10128 65107

Jin, D. K., Shido, K., Kopp, H. G., Petit, I., Shmelkov, S. V., Young, L. M., et al. (2006). Cytokine-mediated deployment of SDF-1 induces revascularization through recruitment of CXCR4+ hemangiocytes. Nat. Med. 12, 557-567. doi: $10.1038 / \mathrm{nm} 1400$

Jin, X., Jeon, H. Y., Joo, K. M., Kim, J. K., Jin, J., Kim, S. H., et al. (2011). Frizzled 4 regulates stemness and invasiveness of migrating glioma cells established by serial intracranial transplantation. Cancer Res. 71, 3066-3075. doi: 10.1158/00085472.CAN-10-1495

Jin-qiao, S., Bin, S., Wen-hao, Z., and Yi, Y. (2009). Basic fibroblast growth factor stimulates the proliferation and differentiation of neural stem cells in neonatal rats after ischemic brain injury. Brain Dev. 31, 331-40. doi: 10.1016/j.braindev.2008.06.005

Jung, M. J., Rho, J. K., Kim, Y. M., Jung, J. E., Jin, Y. B., Ko, Y. G., et al. (2013). Upregulation of CXCR4 is functionally crucial for maintenance of stemness in drug-resistant non-small cell lung cancer cells. Oncogene 32, 209-221. doi: 10.1038/onc. 2012.37

Kalatskaya, I., Berchiche, Y. A., Gravel, S., Limberg, B. J., Rosenbaum, J. S., and Heveker, N. (2009). AMD3100 is a CXCR7 ligand with allosteric agonist properties. Mol. Pharmacol. 75, 1240-1247. doi: 10.1124/mol.108.053389

Kaplan, R. N., Psaila, B., and Lyden, D. (2007). Niche-to-niche migration of bone-marrow-derived cells. Trends Mol. Med. 13, 72-81. doi 10.1016/j.molmed.2006.12.003

Keunen, O., Johansson, M., Oudin, A., Sanzey, M., Rahim, S. A., Fack, F., et al. (2011). Anti-VEGF treatment reduces blood supply and increases tumor cell invasion in glioblastoma. Proc. Natl. Acad. Sci. U.S.A. 108, 3749-3754. doi 10.1073/pnas.1014480108

Kim, J., Yip, M. L., Shen, X., Li, H., Hsin, L. Y., Labarge, S., et al. (2012). Identification of anti-malarial compounds as novel antagonists to chemokine receptor CXCR4 in pancreatic cancer cells. PLoS ONE 7:e31004. doi: 10.1371/journal.pone.0031004

Kioi, M., Vogel, H., Schultz, G., Hoffman, R. M., Harsh, G. R., and Brown, J. M. (2010). Inhibition of vasculogenesis, but not angiogenesis, prevents the recurrence of glioblastoma after irradiation in mice. J. Clin. Invest. 120, 694-705. doi 10.1172/JCI40283

Klarenbeek, A. M. D., Blanchetot, C., Saunders, M., van der Woning, S., Smit, M., de Haard, H., et al. (2012). Targeting chemokines and chemokine receptors with antibodies. Drug Discov. Today Technol. 9, e227-314. doi: 10.1016/j.ddtec.2012.05.003

Kuhne, M. R., Mulvey, T., Belanger, B., Chen, S., Pan, C., Chong, C., et al. (2013). BMS-936564/MDX-1338: a fully human anti-CXCR4 antibody induces apoptosis in vitro and shows antitumor activity in vivo in hematologic malignancies. Clin. Cancer Res. 19, 357-366. doi: 10.1158/1078-0432.CCR-12-2333

Laywell, E. D., Steindler, D. A., and Silver, D. J. (2007). Astrocytic stem cells in the adult brain. Neurosurg. Clin. N. Am. 18, 21-30. doi: 10.1016/j.nec.2006.10.003

Lee, C. C., Lai, J. H., Hueng, D. Y., Ma, H. I., Chung, Y., Sun, Y. Y., et al. (2013). Disrupting the CXCL12/CXCR4 axis disturbs the characteristics of glioblastoma stem-like cells of rat RG2 glioblastoma. Cancer Cell Int. 13, 85. doi: 10.1186/14752867-13-85

Lee, J., Kotliarova, S., Kotliarov, Y., Li, A., Su, Q., Donin, N. M., et al. (2006). Tumor stem cells derived from glioblastomas cultured in bFGF and EGF more closely mirror the phenotype and genotype of primary tumors than do serum-cultured cell lines. Cancer Cell 9, 391-403. doi: 10.1016/j.ccr.2006.03.030

Levoye, A., Balabanian, K., Baleux, F., Bachelerie, F., and Lagane, B. (2009). CXCR7 heterodimerizes with CXCR4 and regulates CXCL12-mediated G protein signaling. Blood 113, 6085-6093. doi: 10.1182/blood-2008-12-196618

Li, M., and Ransohoff, R. M. (2009). The roles of chemokine CXCL12 in embryonic and brain tumor angiogenesis. Semin Cancer Biol 19, 111-115. doi: 10.1016/j.semcancer.2008.11.001

Liang, Z., Wu, H., Reddy, S., Zhu, A., Wang, S., Blevins, D., et al. (2007). Blockade of invasion and metastasis of breast cancer cells via targeting CXCR4 with an artificial microRNA. Biochem. Biophys. Res. Commun. 363, 542-546. doi: 10.1016/j.bbrc.2007.09.007

Liang, Z., Wu, T., Lou, H., Yu, X., Taichman, R. S., Lau, S. K., et al. (2004). Inhibition of breast cancer metastasis by selective synthetic polypeptide against CXCR4. Cancer Res. 64, 4302-4308. doi: 10.1158/0008-5472.CAN-03-3958
Liang, Z., Zhan, W., Zhu, A., Yoon, Y., Lin, S., Sasaki, M., et al. (2012). Development of a unique small molecule modulator of CXCR4. PLoS ONE 7:e34038. doi: 10.1371/journal.pone.0034038

Ling, X., Spaeth, E., Chen, Y., Shi, Y., Zhang, W., Schober, W., et al. (2013). The CXCR4 antagonist AMD3465 regulates oncogenic signaling and invasiveness in vitro and prevents breast cancer growth and metastasis in vivo. PLoS ONE 8:e58426. doi: 10.1371/journal.pone.0058426

Lippitz, B. E. (2013). Cytokine patterns in patients with cancer: a systematic review. Lancet Oncol. 14, e218-28. doi: 10.1016/S1470-2045(12)70582-X

Liu, C., Luo, D., Reynolds, B. A., Meher, G., Katritzky, A. R., Lu, B., et al. (2011). Chemokine receptor CXCR3 promotes growth of glioma. Carcinogenesis 32, 129 137. doi: 10.1093/carcin/bgq224

Liu, C., Pham, K., Luo, D., Reynolds, B. A., Hothi, P., Foltz, G., et al. (2013). Expression and functional heterogeneity of chemokine receptors CXCR4 and CXCR7 in primary patient-derived glioblastoma cells. PLoS ONE 8:e59750. doi: 10.1371/journal.pone.0059750

Liu, G., Yuan, X., Zeng, Z., Tunici, P., Ng, H., Abdulkadir, I. R., et al. (2006). Analysis of gene expression and chemoresistance of CD133+ cancer stem cells in glioblastoma. Mol. Cancer 5, 67. doi: 10.1186/1476-4598-5-67

Liu, S. C., Alomran, R., Chernikova, S. B., Lartey, F., Stafford, J., Jang, T. C., et al. (2014). Blockade of SDF-1 after irradiation inhibits tumor recurrences of autochthonous brain tumors in rats. Neuro Oncol. 16, 21-28. doi: 10.1093/neuonc/not149

Liu, Y., Carson-Walter, E. B., Cooper, A., Winans, B. N., Johnson, M. D., and Walter, K. A. (2010). Vascular gene expression patterns are conserved in primary and metastatic brain tumors. J. Neurooncol. 99, 13-24. doi: 10.1007/s11060-0090105-0

Luker, K. E., Gupta, M., Steele, J. M., Foerster, B. R., and Luker, G. D. (2009). Imaging ligand-dependent activation of CXCR7. Neoplasia 11, 1022-1035.

Ma, Q., Jones, D., Borghesani, P. R., Segal, R. A., Nagasawa, T., Kishimoto, T., et al. (1998). Springer, Impaired B-lymphopoiesis, myelopoiesis, and derailed cerebellar neuron migration in CXCR4- and SDF-1-deficient mice. Proc. Natl. Acad. Sci. U.S.A. 95, 9448-9453. doi: 10.1073/pnas.95.16.9448

Maderna, E., Salmaggi, A., Calatozzolo, C., Limido, L., and Pollo, B. (2007). Nestin, PDGFRbeta, CXCL12 and VEGF in glioma patients: different profiles of (pro-angiogenic) molecule expression are related with tumor grade and may provide prognostic information. Cancer Biol. Ther. 6, 1018-1024. doi: $10.4161 /$ cbt.6.7.4362

Marchesi, F., Monti, P., Leone, B. E., Zerbi, A., Vecchi, A., Piemonti, L., et al. (2004). Increased survival, proliferation, and migration in metastatic human pancreatic tumor cells expressing functional CXCR4. Cancer Res. 64, 8420-8427. doi: 10.1158/0008-5472.CAN-04-1343

Masuda, M., Nakashima, H., Ueda, T., Naba, H., Ikoma, R., Otaka, A., et al. (1992). A novel anti-HIV synthetic peptide, T-22 ([Tyr5,12,Lys7]-polyphemusin II). Biochem. Biophys. Res. Commun. 189, 845-850. doi: 10.1016/0006291X(92)92280-B

Mazzinghi, B., Ronconi, E., Lazzeri, E., Sagrinati, C., Ballerini, L., Angelotti, M. L., et al. (2008). Essential but differential role for CXCR4 and CXCR7 in the therapeutic homing of human renal progenitor cells. J. Exp. Med. 205, 479-90. doi: $10.1084 /$ jem. 20071903

Miao, Z., Luker, K. E., Summers, B. C., Berahovich, R., Bhojani, M. S., Rehemtulla, A., et al. (2007). CXCR7 (RDC1) promotes breast and lung tumor growth in vivo and is expressed on tumor-associated vasculature. Proc. Natl. Acad. Sci. U.S.A. 104, 15735-15740. doi: 10.1073/pnas.0610444104

Miles, D. K., and Kernie, S. G. (2008). Hypoxic-ischemic brain injury activates early hippocampal stem/progenitor cells to replace vulnerable neuroblasts. Hippocampus 18, 793-806. doi: 10.1002/hipo.20439

Miller, F. D., and Gauthier-Fisher, A. (2009). Home at last: neural stem cell niches defined. Cell Stem. Cell 4, 507-510. doi: 10.1016/j.stem.2009. 05.008

Mimeault, M., Hauke, R., Mehta, P. P., and Batra, S. K. (2007). Recent advances in cancer stem/progenitor cell research: therapeutic implications for overcoming resistance to the most aggressive cancers. J. Cell. Mol. Med. 11, 981-1011. doi: 10.1111/j.1582-4934.2007.00088.x

Monnier, J., Boissan, M., L'Helgoualc'h, A., Lacombe, M. L., Turlin, B., ZucmanRossi, J., et al. (2012). CXCR7 is up-regulated in human and murine hepatocellular carcinoma and is specifically expressed by endothelial cells. Eur. J. Cancer 48, 138-148. doi: 10.1016/j.ejca.2011.06.044 
Mosi, R. M., Anastassova, V., Cox, J., Darkes, M. C., Idzan, S. R., Labrecque, J., et al. (2012). The molecular pharmacology of AMD11070: an orally bioavailable CXCR4 HIV entry inhibitor. Biochem. Pharmacol. 83, 472-479. doi: 10.1016/j.bcp.2011.11.020

Muller, A., Homey, B., Soto, H., Ge, N., Catron, D., Buchanan, M. E., et al. (2001) Involvement of chemokine receptors in breast cancer metastasis. Nature 410, 50-56. doi: 10.1038/35065016

Munson, J. M., Bellamkonda, R. V., and Swartz, M. A. (2013). Interstitial flow in a $3 \mathrm{D}$ microenvironment increases glioma invasion by a CXCR4-dependent mechanism. Cancer Res. 73, 1536-1546. doi: 10.1158/0008-5472.CAN$12-2838$

Naumann, U., Cameroni, E., Pruenster, M., Mahabaleshwar, H., Raz, E., Zerwes, H. G., et al. (2010). CXCR7 functions as a scavenger for CXCL12 and CXCL11. PLoS ONE 5:e9175. doi: 10.1371/journal.pone.0009175

O’Boyle, G., Swidenbank, I., Marshall, H., Barker, C. E., Armstrong, J., White S. A., et al. (2013). Inhibition of CXCR4-CXCL12 chemotaxis in melanoma by AMD11070. Br. J. Cancer 108, 1634-1640. doi: 10.1038/bjc.2013.124

Odemis, V., Boosmann, K., Heinen, A., Kury, P., and Engele, J. (2010). CXCR7 is an active component of SDF-1 signalling in astrocytes and Schwann cells. J. Cell Sci. 123, 1081-1088. doi: 10.1242/jcs.062810

Odemis, V., Lipfert, J., Kraft, R., Hajek, P., Abraham, G., Hattermann, K., et al. (2012). The presumed atypical chemokine receptor CXCR7 signals through $\mathrm{G}(\mathrm{i} / \mathrm{o})$ proteins in primary rodent astrocytes and human glioma cells. Glia 60, 372-381. doi: 10.1002/glia.22271

Orimo, A., Gupta, P. B., Sgroi, D. C., Arenzana-Seisdedos, F., Delaunay, T., Naeem R., et al. (2005). Stromal fibroblasts present in invasive human breast carcinomas promote tumor growth and angiogenesis through elevated SDF-1/CXCL12 secretion. Cell 121, 335-348. doi: 10.1016/j.cell.2005.02.034

Pattarozzi, A., Gatti, M., Barbieri, F., Wurth, R., Porcile, C., Lunardi, G. et al. (2008). 17beta-estradiol promotes breast cancer cell proliferation-inducing stromal cell-derived factor-1-mediated epidermal growth factor receptor transactivation: reversal by gefitinib pretreatment. Mol. Pharmacol. 73, 191-202. doi: 10.1124/mol.107.039974

Peled, A., Abraham, M., Avivi, I., Rowe, J. M., Beider, K., Wald, H., et al. (2014). The high-affinity CXCR4 antagonist BKT140 is safe and induces a robust mobilization of human CD34+ cells in patients with multiple myeloma. Clin. Cancer Res. 20, 469-479. doi: 10.1158/1078-0432.CCR-13-1302

Penuelas, S., Anido, J., Prieto-Sanchez, R. M., Folch, G., Barba, I., Cuartas, I., et al. (2009). TGF-beta increases glioma-initiating cell self-renewal through the induction of LIF in human glioblastoma. Cancer Cell 15, 315-327. doi: 10.1016/j.ccr.2009.02.011

Petit, I., Jin, D., and Rafii, S. (2007). The SDF-1-CXCR4 signaling pathway: a molecular hub modulating neo-angiogenesis. Trends Immunol. 28, 299-307. doi: 10.1016/j.it.2007.05.007

Piccirillo, S. G., Reynolds, B. A., Zanetti, N., Lamorte, G., Binda, E., Broggi, G., et al. (2006). Bone morphogenetic proteins inhibit the tumorigenic potential of human brain tumour-initiating cells. Nature 444, 761-765. doi: 10.1038/nature 05349

Ping, Y. F., Yao, X. H., Jiang, J. Y., Zhao, L. T., Yu, S. C., Jiang, T., et al. (2011). The chemokine CXCL12 and its receptor CXCR4 promote glioma stem cell-mediated VEGF production and tumour angiogenesis via PI3K/AKT signalling. J. Pathol. 224, 344-354. doi: 10.1002/path.2908

Rajagopal, S., Kim, J., Ahn, S., Craig, S., Lam, C. M., Gerard, N. P., et al. (2010). Betaarrestin- but not G protein-mediated signaling by the "decoy" receptor CXCR7. Proc. Natl. Acad. Sci. U.S.A. 107, 628-632. doi: 10.1073/pnas.0912852107

Ramasamy, S., Narayanan, G., Sankaran, S., Yu, Y. H., and Ahmed, S. (2013). Neural stem cell survival factors. Arch. Biochem. Biophys. 534, 71-87. doi: 10.1016/j.abb.2013.02.004

Redjal, N., Chan, J. A., Segal, R. A., and Kung, A. L. (2006). CXCR4 inhibition synergizes with cytotoxic chemotherapy in gliomas. Clin. Cancer Res. 12, 67656771. doi: 10.1158/1078-0432.CCR-06-1372

Rempel, S. A., Dudas, S., Ge, S., and Gutierrez, J. A. (2000). Identification and localization of the cytokine SDF1 and its receptor, CXC chemokine receptor 4, to regions of necrosis and angiogenesis in human glioblastoma. Clin. Cancer Res. 6, $102-111$.

Ricci-Vitiani, L., Pallini, R., Biffoni, M., Todaro, M., Invernici, G., Cenci, T. Maira, G., et al. (2010). Tumour vascularization via endothelial differentiation of glioblastoma stem-like cells. Nature 468, 824-828. doi: 10.1038/nature09557
Richert, M. M., Vaidya, K. S., Mills, C. N., Wong, D., Korz, W., Hurst, D. R., et al. (2009). Inhibition of CXCR4 by CTCE-9908 inhibits breast cancer metastasis to lung and bone. Oncol. Rep. 21, 761-767. doi: 10.3892/or_00000282

Rodriguez, F. J., Orr, B. A., Ligon, K. L., and Eberhart, C. G. (2012). Neoplastic cells are a rare component in human glioblastoma microvasculature. Oncotarget 3, 98-106.

Rong, Y., Hu, F., Huang, R., Mackman, N., Horowitz, J. M., Jensen, R. L., et al. (2006) Early growth response gene-1 regulates hypoxia-induced expression of tissue factor in glioblastoma multiforme through hypoxia-inducible factor-1-independent mechanisms. Cancer Res. 66, 7067-7074. doi: 10.1158/0008-5472.CAN06-0346

Rostene, W., Guyon, A., Kular, L., Godefroy, D., Barbieri, F., Bajetto, A., et al. (2011). Chemokines and chemokine receptors: new actors in neuroendocrine regulations. Front. Neuroendocrinol. 32:10-24. doi: 10.1016/j.yfrne.2010.07.001

Rostene, W., Kitabgi, P., and Parsadaniantz, S. M. (2007). Chemokines: a new class of neuromodulator? Nat. Rev. Neurosci. 8, 895-903. doi: 10.1038/ $\operatorname{nrn} 2255$

Rubin, J. B., Kung, A. L., Klein, R. S., Chan, J. A., Sun, Y., Schmidt, K., et al. (2003). A small-molecule antagonist of CXCR4 inhibits intracranial growth of primary brain tumors. Proc. Natl. Acad. Sci. U.S.A. 100, 13513-13518. doi: 10.1073/pnas. 2235846100

Ruiz-Ontanon, P., Orgaz, J. L., Aldaz, B., Elosegui-Artola A., Martino, J., Berciano, M. T., et al. (2013). Cellular plasticity confers migratory and invasive advantages to a population of glioblastoma-initiating cells that infiltrate peritumoral tissue. Stem Cells 31, 1075-1085. doi: 10.1002/stem.1349

Salmaggi, A., Boiardi, A., Gelati, M., Russo, A., Calatozzolo, C., Ciusani, E., et al. (2006). and M. De Rossi, Glioblastoma-derived tumorospheres identify a population of tumor stem-like cells with angiogenic potential and enhanced multidrug resistance phenotype. Glia 54, 850-860. doi: 10.1002/glia.20414

Salmaggi, A., Gelati, M., Pollo, B., Marras, C., Silvani, A., Balestrini, M. R., et al. (2005a). CXCL12 expression is predictive of a shorter time to tumor progression in low-grade glioma: a single-institution study in 50 patients. J. Neurooncol. 74, 287-293. doi: 10.1007/s11060-0047327-y

Salmaggi, A., Riva, M., Silvani, A., Merli, R., Tomei, G., Lorusso, L., et al. (2005b) A multicentre prospective collection of newly diagnosed glioblastoma patients in Lombardia, Italy. Neurol. Sci. 26, 227-234. doi: 10.1007/s10072-005-0465-y

Sanchez-Alcaniz, J. A., Haege, S., Mueller, W., Pla, R., Mackay, F., Schulz, S., et al. (2011). Cxcr7 controls neuronal migration by regulating chemokine responsiveness. Neuron 69, 77-90. doi: 10.1016/j.neuron.2010.12.006

Sanchez-Martin, L., Sanchez-Mateos, P., and Cabanas, C. (2013). CXCR7 impact on CXCL12 biology and disease. Trends Mol. Med. 19, 12-22. doi: 10.1016/j.molmed.2012.10.004

Schonemeier, B., Kolodziej, A., Schulz, S., Jacobs, S., Hoellt, V., and Stumm, R. (2008a). Regional and cellular localization of the CXCl12/SDF-1 chemokine receptor CXCR7 in the developing and adult rat brain. J. Comp. Neurol. 510, 207-220. doi: 10.1002/cne.21780

Schonemeier, B., Schulz, S., Hoellt, V., and Stumm, R. (2008b). Enhanced expression of the CXCl12/SDF-1 chemokine receptor CXCR7 after cerebral ischemia in the rat brain. J. Neuroimmunol. 198, 39-45. doi: 10.1016/j.jneuroim.2008.04.010

Schulte, A., Gunther, H. S., Phillips, H. S., Kemming, D., Martens, T., Kharbanda, S., et al. (2011). A distinct subset of glioma cell lines with stem cell-like properties reflects the transcriptional phenotype of glioblastomas and overexpresses CXCR4 as therapeutic target. Glia 59, 590-602. doi: 10.1002/glia.21127

Schutyser, E., Su, Y., Yu, Y., Gouwy, M., Zaja-Milatovic, S., Van Damme, J., et al. (2007). Hypoxia enhances CXCR4 expression in human microvascular endothelial cells and human melanoma cells. Eur Cytokine Netw. 18, 59-70. doi: 10.1684/ecn.2007.0087

Sciaccaluga, M., D’Alessandro, G., Pagani, F., Ferrara, G., Lopez, N., Warr, T., et al. (2013). Functional cross talk between CXCR4 and PDGFR on glioblastoma cells is essential for migration. PLoS ONE 8:e73426. doi: 10.1371/journal.pone.00 73426

Sciume, G., Santoni, A., and Bernardini, G. (2010). Chemokines and glioma: invasion and more. J. Neuroimmunol. 224, 8-12. doi: 10.1016/j.jneuroim.2010. 05.019

Scotton, C. J., Wilson, J. L., Scott, K., Stamp, G., Wilbanks, G. D., Fricker, S., et al. (2002). Multiple actions of the chemokine CXCL12 on epithelial tumor cells in human ovarian cancer. Cancer Res. 62, 5930-5938. 
Shaked, Y., Henke, E., Roodhart, J. M., Mancuso, P., Langenberg, M. H., Colleoni, M., et al. (2008). Rapid chemotherapy-induced acute endothelial progenitor cell mobilization: implications for antiangiogenic drugs as chemosensitizing agents. Cancer Cell 14, 263-273. doi: 10.1016/j.ccr.2008.08.001

Shen, Q., Goderie, S. K., Jin, L., Karanth, N., Sun, Y., Abramova, N., et al. (2004) Endothelial cells stimulate self-renewal and expand neurogenesis of neural stem cells. Science 304, 1338-1340. doi: 10.1126/science.1095505

Shu, H. K., Yoon, Y., Hong, S., Xu, K., Gao, H., Hao, C., et al. (2013). Inhibition of the CXCL12/CXCR4-axis as preventive therapy for radiation-induced pulmonary fibrosis. PLoS ONE 8:e79768. doi: 10.1371/journal.pone.0079768

Sierro, F., Biben, C., Martinez-Munoz, L., Mellado, M., Ransohoff, R. M., Li, M. et al. (2007). Disrupted cardiac development but normal hematopoiesis in mice deficient in the second CXCL12/SDF-1 receptor, CXCR7. Proc. Natl. Acad. Sci. U.S.A. 104, 14759-14764. doi: 10.1073/pnas.0702229104

Singh, A. K., Arya, R. K., Trivedi, A. K., Sanyal, S., Baral, R., Dormond, O., etal. (2013). Chemokine receptor trio: CXCR3, CXCR4 and CXCR7 crosstalk via CXCL11 and CXCL12. Cytokine Growth Factor Rev. 24, 41-49. doi 10.1016/j.cytogfr.2012.08.007

Singh, S. K., Clarke, I. D., Hide, T., and Dirks, P. B. (2004a). Cancer stem cells in nervous system tumors. Oncogene 23, 7267-7273. doi: 10.1038/sj.onc.12 07946

Singh, S. K., Hawkins, C., Clarke, I. D., Squire, J. A., Bayani, J., Hide, T., et al. (2004b). Identification of human brain tumour initiating cells. Nature 432, 396-401. doi: 10.1038 /nature03128

Singh, S. K., Clarke, I. D., Terasaki, M., Bonn, V. E., Hawkins, C., Squire, J., et al. (2003). Identification of a cancer stem cell in human brain tumors. Cancer Res. 63, 5821-588.

Soda, Y., Marumoto, T., Friedmann-Morvinski D., Soda, M., Liu, F., Michiue, H., et al. (2011). Transdifferentiation of glioblastoma cells into vascular endothelial cells. Proc. Natl. Acad. Sci. U.S.A. 108, 4274-4280. doi: 10.1073/pnas.10160 30108

Stumm, R. K., Zhou, C., Ara, T., Lazarini, F., Dubois-Dalcq, M., Nagasawa, T., et al. (2003). CXCR4 regulates interneuron migration in the developing neocortex. $J$. Neurosci. 23, 5123-5130.

Stupp, R., Mason, W. P., van den Bent, M. J., Weller, M., Fisher, B., Taphoorn, M. J., et al. (2005). Radiotherapy plus concomitant and adjuvant temozolomide for glioblastoma. N. Engl. J. Med. 352, 987-996. doi: 10.1056/NEJMoa0 43330

Sun, Y., Cheng, Z., Ma, L., and Pei, G. (2002). Beta-arrestin2 is critically involved in CXCR4-mediated chemotaxis, and this is mediated by its enhancement of p38 MAPK activation. J. Biol. Chem. 277, 49212-49219. doi: 10.1074/jbc.M2072 94200

Tang, D. G. (2012). Understanding cancer stem cell heterogeneity and plasticity. Cell Res. 22, 457-472. doi: 10.1038/cr.2012.13

Teicher, B. A., and Fricker, S. P. (2010). CXCL12 (SDF-1)/CXCR4 pathway in cancer. Clin. Cancer Res. 16, 2927-2931. doi: 10.1158/1078-0432.CCR-09-2329

Thelen, M., and Thelen, S. (2008). CXCR7, CXCR4 and CXCL12: an eccentric trio? J. Neuroimmunol. 198, 9-13. doi: 10.1016/j.jneuroim.2008.04.020

Tiveron, M. C., Boutin, C., Daou, P., Moepps, B., and Cremer, H. (2010). Expression and function of CXCR7 in the mouse forebrain. J. Neuroimmunol. 224, 72-79. doi: 10.1016/j.jneuroim.2010.05.011

Tiveron, M. C., Rossel, M., Moepps, B., Zhang, Y. L., Seidenfaden, R., Favor, J., et al. (2006). Molecular interaction between projection neuron precursors and invading interneurons via stromal-derived factor 1 (CXCL12)/CXCR4 signaling in the cortical subventricular zone/intermediate zone. J. Neurosci. 26, 13273 13278. doi: 10.1523/JNEUROSCI.4162-06.2006

To, L. B., Levesque, J. P., and Herbert, K. E. (2011). How I treat patients who mobilize hematopoietic stem cells poorly. Blood 118, 4530-4540. doi: 10.1182/blood-201106-318220

Uemae, Y., Ishikawa, E., Osuka, S., Matsuda, M., Sakamoto, N., Takano, S., et al. (2014). CXCL12 secreted from glioma stem cells regulates their proliferation. $J$. Neurooncol. 117, 43-51. doi: 10.1007/s11060-014-1364-y

Uto-Konomi, A., McKibben, B., Wirtz, J., Sato, Y., Takano, A., Nanki, T., et al. (2013). CXCR7 agonists inhibit the function of CXCL12 by down-regulation of CXCR4. Biochem. Biophys. Res. Commun. 431, 772-776. doi: 10.1016/j.bbrc.2013. 01.032

Vitale, R. M., Gatti, M., Carbone, M., Barbieri, F., Felicita, V., Gavagnin, M., et al. (2013). Minimalist hybrid ligand/receptor-based pharmacophore model for CXCR4 applied to a small-library of marine natural products led to the identification of phidianidine a as a new CXCR4 ligand exhibiting antagonist activity. ACS Chem. Biol. 8, 2762-2770. doi: 10.1021/cb400521b

Wakimoto, H., Mohapatra, G., Kanai, R., Curry, W. T. Jr., Yip, S., Nitta, M., et al. (2012). Maintenance of primary tumor phenotype and genotype in glioblastoma stem cells. Neuro. Oncol. 14, 132-144. doi: 10.1093/neuonc/nor195

Walters, M. J., Ebsworth, K., Berahovich, R. D., Penfold, M. E., Liu, S. C., R. Al Omran, et al. (2014). Inhibition of CXCR7 extends survival following irradiation of brain tumours in mice and rats. Br. J. Cancer 110, 1179-1188. doi: 10.1038/bjc. 2013.830

Wang, J., Wakeman, T. P., Lathia, J. D., Hjelmeland, A. B., Wang, X. F., White, R. R., et al. (2010a). Notch promotes radioresistance of glioma stem cells. Stem Cells 28, 17-28. doi: 10.1002/stem.261

Wang, R., Chadalavada, K., Wilshire, J., Kowalik, U., Hovinga, K. E., Geber, A., et al. (2010b). Glioblastoma stem-like cells give rise to tumour endothelium. Nature 468, 829-833. doi: 10.1038/nature09624

Wang, Y., Li, G., Stanco, A., Long, J. E., Crawford, D., Potter, G. B., et al. (2011). CXCR4 and CXCR7 have distinct functions in regulating interneuron migration. Neuron 69, 61-76. doi: 10.1016/j.neuron.2010.12.005

Wang, Z., Ma, Q., Liu, Q., Yu, H., Zhao, L., Shen, S., et al. (2008). Blockade of SDF-1/CXCR4 signalling inhibits pancreatic cancer progression in vitro via inactivation of canonical Wnt pathway. Br. J. Cancer 99, 1695-1703. doi: 10.1038/sj.bjc.6604745

Wei, Y., Jiang, Y., Zou, F., Liu, Y., Wang, S., Xu, N., et al. (2013). Activation of PI3K/Akt pathway by CD133-p85 interaction promotes tumorigenic capacity of glioma stem cells. Proc. Natl. Acad. Sci. U.S.A. 110, 6829-6834. doi: $10.1073 /$ pnas. 1217002110

Wijtmans, M., Maussang, D., Sirci, F., Scholten, D. J., Canals, M., Mujic-Delic A. et al. (2012). Synthesis, modeling and functional activity of substituted styreneamides as small-molecule CXCR7 agonists. Eur. J. Med. Chem. 51, 184-192. doi: 10.1016/j.ejmech.2012.02.041

Woerner, B. M., Warrington, N. M., Kung, A. L., Perry, A., and Rubin, J. B. (2005) Widespread CXCR4 activation in astrocytomas revealed by phospho-CXCR4specific antibodies. Cancer Res. 65, 11392-11399. doi: 10.1158/0008-5472.CAN05-0847

Wong, D., and Korz, W. (2008). Translating an antagonist of chemokine receptor CXCR4: from bench to bedside. Clin. Cancer Res. 14, 7975-7980. doi: 10.1158/1078-0432.CCR-07-4846

Wu, B., Chien, E. Y., Mol, C. D., Fenalti, G., Liu, W., Katritch, V., et al. (2010). Structures of the CXCR4 chemokine GPCR with small-molecule and cyclic peptide antagonists. Science 330, 1066-1071. doi: 10.1126/science.11 94396

Wu, M., Chen, Q., Li, D., Li, X., Huang, C., Tang, Y., et al. (2008). LRRC4 inhibits human glioblastoma cells proliferation, invasion, and proMMP-2 activation by reducing SDF-1 alpha/CXCR4-mediated ERK1/2 and Akt signaling pathways. J. Cell. Biochem. 103, 245-255. doi: 10.1002/jcb.21400

Wurth, R., Barbieri, F., and Florio, T. (2014). New molecules and old drugs as emerging approaches to selectively target human glioblastoma cancer stem cells. Biomed. Res. Int. 2014, 126586. doi: 10.1155/2014/126586

Wurth, R., Barbieri, F., Bajetto, A., Pattarozzi, A., Gatti, M., Porcile, C., et al (2011). Expression of CXCR7 chemokine receptor in human meningioma cells and in intratumoral microvasculature. J. Neuroimmunol. 234, 115-123. doi: 10.1016/j.jneuroim.2011.01.006

Yang, Z., and Levison, S. W. (2006). Hypoxia/ischemia expands the regenerative capacity of progenitors in the perinatal subventricular zone. Neuroscience 139, 555-564. doi: 10.1016/j.neuroscience.2005.12.059

Yao, X., Ping, Y., Liu, Y., Chen, K., Yoshimura, T., Liu, M., et al. (2013). Vascular endothelial growth factor receptor 2 (VEGFR-2) plays a key role in vasculogenic mimicry formation, neovascularization and tumor initiation by Glioma stem-like cells. PLoS ONE 8:e57188. doi: 10.1371/journal.pone.0057188

Yoon, Y., Liang, Z., Zhang, X., Choe, M., Zhu, A., Cho, H. T., et al. (2007) CXC chemokine receptor- 4 antagonist blocks both growth of primary tumor and metastasis of head and neck cancer in xenograft mouse models. Cancer Res. 67, 7518-7524. doi: 10.1158/0008-5472.CAN-06-2263

Yoshikawa, Y., Oishi, S., Kubo, T., Tanahara, N., Fujii, N., and Furuya, T. (2013). Optimized method of G-protein-coupled receptor homology modeling: its application to the discovery of novel CXCR7 ligands. J. Med. Chem. 56, 4236-4251. doi: $10.1021 / \mathrm{jm} 400307 \mathrm{y}$ 
Zabel, B. A., Lewen, S., Berahovich, R. D., Jaen, J. C., and Schall, T. J. (2011). The novel chemokine receptor CXCR7 regulates trans-endothelial migration of cancer cells. Mol. Cancer 10, 73. doi: 10.1186/1476-4598-10-73

Zabel, B. A., Wang, Y., Lewen, S., Berahovich, R. D., Penfold, M. E., Zhang, P., et al. (2009). Elucidation of CXCR7-mediated signaling events and inhibition of CXCR4-mediated tumor cell transendothelial migration by CXCR7 ligands. J. Immunol. 183, 3204-3211. doi: 10.4049/jimmunol.0900269

Zagzag, D., Esencay, M., Mendez, O., Yee, H., Smirnova, I., Huang, Y., et al. (2008). Hypoxia- and vascular endothelial growth factor-induced stromal cell-derived factor-lalpha/CXCR4 expression in glioblastomas: one plausible explanation of Scherer's structures. Am. J. Pathol. 173, 545-560. doi: 10.2353/ajpath.2008. 071197

Zhang, J., Sarkar, S., and Yong, V. W. (2005). The chemokine stromal cell derived factor-1 (CXCL12) promotes glioma invasiveness through MT2-matrix metalloproteinase. Carcinogenesis 26, 2069-2077. doi: 10.1093/carcin/bgil83

Zhang, S. S., Han, Z. P., Jing, Y. Y., Tao, S. F., Li, T. J., Wang, H., et al. (2012). CD133(+)CXCR4 $(+)$ colon cancer cells exhibit metastatic potential and predict poor prognosis of patients. BMC Med. 10:85. doi: 10.1186/1741-70 15-10-85

Zhao, D., Najbauer, J., Garcia, E., Metz, M. Z., Gutova, M., Glackin, C. A., et al. (2008). Neural stem cell tropism to glioma: critical role of tumor hypoxia. Mol. Cancer Res. 6, 1819-1829. doi: 10.1158/1541-7786.MCR-08-0146

Zhong, C., Wang, J., Li, B., Xiang, H., Ultsch, M., Coons, M., et al. (2013). Development and preclinical characterization of a humanized antibody targeting CXCL12. Clin. Cancer Res. 19, 4433-4445. doi: 10.1158/1078-0432.CCR13-0943

Zhou, Y., Larsen, P. H., Hao, C., and Yong, V. W. (2002). CXCR4 is a major chemokine receptor on glioma cells and mediates their survival. J. Biol. Chem. 277, 4948149487. doi: 10.1074/jbc.M206222200

Zhu, Y., and Murakami, F. (2012). Chemokine CXCL12 and its receptors in the developing central nervous system: emerging themes and future perspectives. Dev. Neurobiol. 72, 1349-1362. doi: 10.1002/dneu.22041
Zhu, Y., Matsumoto, T., Mikami, S., Nagasawa, T., and Murakami, F. (2009) SDF1/CXCR4 signalling regulates two distinct processes of precerebellar neuronal migration and its depletion leads to abnormal pontine nuclei formation. Development 136, 1919-1928. doi: 10.1242/dev.032276

Zlotnik, A. (2006). Chemokines and cancer. Int. J. Cancer 119, 2026-2029. doi: $10.1002 /$ ijc. 22024

Zlotnik, A. (2008). New insights on the role of CXCR4 in cancer metastasis. J. Pathol. 215, 211-213. doi: 10.1002/path.2350

Zlotnik, A., Burkhardt, A. M., and Homey, B. (2011). Homeostatic chemokine receptors and organ-specific metastasis. Nat. Rev. Immunol. 11, 597-606. doi: $10.1038 /$ nri3049

Zou, Y. R., Kottmann, A. H., Kuroda, M., Taniuchi, I., and Littman, D. R. (1998). Function of the chemokine receptor CXCR4 in haematopoiesis and in cerebellar development. Nature 393, 595-599. doi: 10.1038/31269

Conflict of Interest Statement: The authors declare that the research was conducted in the absence of any commercial or financial relationships that could be construed as a potential conflict of interest.

Received: 27 March 2014; accepted: 06 May 2014; published online: 28 May 2014.

Citation: Würth R, Bajetto A, Harrison JK, Barbieri F and Florio T (2014) CXCL12 modulation of CXCR4 and CXCR7 activity in human glioblastoma stem-like cells and regulation of the tumor microenvironment. Front. Cell. Neurosci. 8:144. doi: 10.3389/fncel.2014.00144

This article was submitted to the journal Frontiers in Cellular Neuroscience.

Copyright (C) 2014 Würth, Bajetto, Harrison, Barbieri and Florio. This is an openaccess article distributed under the terms of the Creative Commons Attribution License (CC BY). The use, distribution or reproduction in other forums is permitted, provided the original author(s) or licensor are credited and that the original publication in this journal is cited, in accordance with accepted academic practice. No use, distribution or reproduction is permitted which does not comply with these terms. 